\title{
Laminin $\beta 2$ Chain Regulates Cell Cycle Dynamics in the Developing Retina
}

\author{
Dmitri Serjanov, Galina Bachay, Dale D. Hunter and William J. Brunken* \\ Department of Ophthalmology and Visual Sciences, Upstate Medical University, Syracuse, NY, United States
}

Vertebrate retinal development follows a highly stereotyped pattern, in which the retinal progenitor cells (RPCs) give rise to all retinal types in a conserved temporal sequence. Ensuring the proper control over RPC cell cycle exit and re-entry is, therefore, crucially important for the generation of properly functioning retina. In this study, we demonstrate that laminins, indispensible ECM components, at the retinal surface, regulate the mechanisms determining whether RPCs generate proliferative or post-mitotic progeny. In vivo deletion of laminin $\beta 2$ in mice resulted in disturbing the RPC cell cycle dynamics, and premature cell cycle exit. Specifically, the RPC S-phase is shortened, with increased numbers of cells present in its late stages. This is followed by an accelerated G2-phase, leading to faster M-phase entry. Finally, the M-phase is extended, with RPCs dwelling longer in prophase. Addition of exogenous $\beta 2$-containing laminins to laminin $\beta 2$-deficient

\section{OPEN ACCESS}

Edited by:

Silvia C. Finnemann,

Fordham University, United States

Reviewed by:

Jakub Konrad Famulski,

University of Kentucky, United States

Ira Daar,

National Cancer Institute (NCl),

United States

*Correspondence:

William J. Brunken

brunkenw@upstate.edu

Specialty section:

This article was submitted to Cell Adhesion and Migration, a section of the journal Frontiers in Cell and Developmental

Biology

Received: 26 October 2021 Accepted: 20 December 2021

Published: 12 January 2022

Citation:

Serjanov $D$, Bachay G, Hunter $D D$ and Brunken WJ (2022) Laminin $\beta 2$ Chain Regulates Cell Cycle Dynamics in the Developing Retina. Front. Cell Dev. Biol. 9:802593. doi: 10.3389/fcell.2021.802593 retinal explants restored the appropriate RPC cell cycle dynamics, as well as $S$ and M-phase progression, leading to proper cell cycle re-entry. Moreover, we show that disruption of dystroglycan, a laminin receptor, phenocopies the laminin $\beta 2$ deletion cell cycle phenotype. Together, our findings suggest that dystroglycan-mediated ECM signaling plays a critical role in regulating the RPC cell cycle dynamics, and the ensuing cell fate decisions.

Keywords: extracellular matrix, laminin, dystroglycan (DG), cell cycle, retinal progenitor cell (RPC), retinal development

\section{INTRODUCTION}

The retina is a highly structured portion of the central nervous system (CNS). During vertebrate retinal development, retinal progenitor cells (RPCs) give rise to all retinal cell types in a conserved temporal sequence. With each cell cycle, a subpopulation of RPCs leaves the cells cycle to become retinal neurons. The first retinal cells to exit the cell cycle are ganglion cells, followed by overlapping waves of differentiating horizontal cells, amacrine cells, cone photoreceptors, rod photoreceptors, bipolar cells, and Müller glia (R. W. Young, 1985; Turner and Cepko, 1987; Holt et al., 1988; Turner et al., 1990). The balance between RPC self-renewal and differentiation is of great importance to ensure the proper development and organization of the retina and this orderly array of cell fates.

The RPC fate choice is tightly regulated by a number of intrinsic and extrinsic cues. Mitotic spindle orientation has been strongly linked to cell fate in various systems (Huttner and Kosodo, 2005; Morin and Bellaiche, 2011). We have previously reported that $\beta 2$-containing laminins modulate the RPC fate by modulating their mitotic axis (Serjanov et al., 2018). However, mitotic spindle orientation is not the only factor regulating cell fate decisions. Cell cycle dynamics have been shown to be of crucial importance in governing the cell fate determination in CNS progenitors (Calegari, 2003; Calegari, 2005; Baye and Link, 2007a; Baye and Link, 2007b; Pilaz 


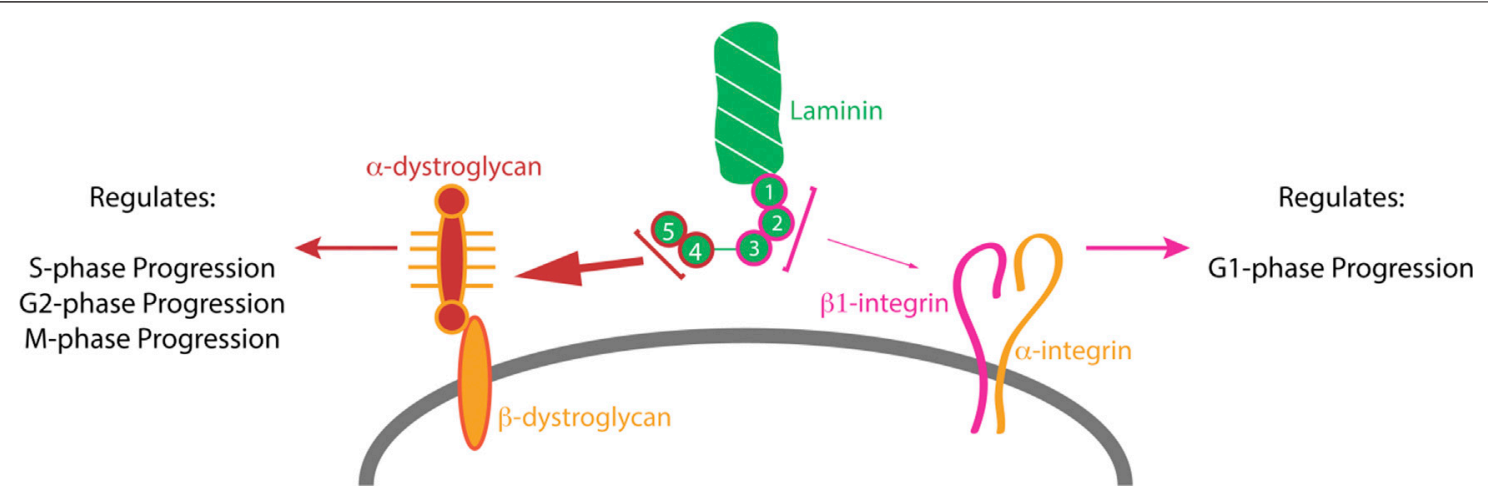

GRAPHICAL ABSTRACT |

et al., 2009). The cell cycle consists of four distinct phases. DNA duplication occurs during the synthesis phase (S-phase), and separation of duplicate chromosomes between two daughter cells occurs in mitosis (M-phase). S and M-phases are separated by two gap phases-G1 and G2. G1 occurs between mitosis and the succeeding S-phase, while G2 lies between S and M-phases. Earlier studies noted extended G1 duration of the radial glia (RG) correlated with the timing of neurogenesis (Calegari, 2003; Calegari, 2005; Baye and Link, 2007a; Baye and Link, 2007b; Pilaz et al., 2009), suggesting that cell cycle timing plays a role in cell fate determination. A later study determined that G1 extension is associated with the restricted intermediate progenitor cells (IPCs), and that the observed progenitor population-wide G1 lengthening is associated with the increased presence of these cells (Arai et al., 2011). Both RG and IPCs that underwent terminal division displayed shortened S-phase length with cells presumably spending less time error checking. Extended mitosis duration has also been observed in conditions associated with premature progenitor differentiation such as lissencephaly and microcephaly (Pilaz et al., 2016; Bershteyn et al., 2017).

Various ECM components such as collagens (Koohestani et al., 2013) and laminins (Domogatskaya et al., 2008), as well as their receptors (Clements et al., 2017), have been shown to affect cell proliferation, though the exact mechanisms of these interactions remain relatively unknown. A link between ECM rigidity and cell cycle regulators had been noted previously (Gerard and Goldbeter, 2014). Taken together, all these data suggest that ECM regulates cell cycle dynamics as well as cell fate via a combination of molecular signaling and biophysical interactions with cells. Previous studies demonstrated that laminins, which are indispensable components of the basement membrane assembly, play important roles throughout retinal development. Laminins, heterotrimeric proteins, containing an $\alpha$, a $\beta$ and a $\gamma$ chain are produced by the retinal neural epithelium early in development and then later by Müller cells (Libby et al., 1997). $\beta 2$-containing laminins are indispensable for the formation of the inner limiting membrane (ILM) but are not for other retinal basement membranes such as vascular and Bruch's (PinzónDuarte et al., 2010). $\beta 2$-containing laminins have been shown to play a role in the development of rod and bipolar cell production (Hunter et al., 1992; Hunter and Brunken, 1997). Genetic ablation of the laminin $\beta 2$ subunit results in a host of retinal developmental abnormalities including: retinal dysplasia (Pinzón-Duarte et al., 2010); photoreceptor synapse malformation and instability (Libby et al., 1999; Hunter et al., 2019); dysgenesis of dopaminergic amacrine cells (Denés et al., 2007); and vascular development (Biswas et al., 2017; Biswas et al., 2018).

In particular, $\beta 2$-containing laminins in the ILM are critical components for a wide variety of cell-matrix interactions. $\beta 2$ containing laminins were identified as substrates for integrinmediated astrocyte migration (Gnanaguru et al., 2013) as well an attachment site for Müller cells thereby providing polarity cue for the normal distribution of aquaporin channels (Hirrlinger et al., 2011). Moreover, Lamb2 deletion resulted in the loss of basal processes from RPCs, producing an IPCslike morphology with disruptions in the cytokinesis and a premature cell cycle exit with a concomitant overproduction of rods at the expenses of later born cell types (Serjanov et al., 2018). Because of the critical role ILM laminins play in cellular processes of cells adherent to it, we investigated the effects of $\beta 2$-containing laminins on the RPC cell cycle dynamics.

In this study, we determined the cell cycle dynamics of the RPCs in postnatal WT mouse retina, and compared them with those of the Lamb2 $2^{-/}$animals in vivo. Here, we show that deletion of laminin $\beta 2$ results in a substantial decrease of the RPC S and G2-phase lengths, as well as extended M-phase durations. Ultimately, these changes result in an increased rate of cell cycle exit. We further analyzed the effects of $\beta 2$ containing laminins on RPC cell cycle using the organotypic retinal culture approach, and showed that addition of exogenous $\beta 2$-containing laminin to the retinal surface ex vivo rescues the cell cycle dynamics. Furthermore, we identified the laminin receptor dystroglycan (DG) as the receptor mediating the ECM-RPC signaling responsible for the observed cell cycle changes. Our data suggest a mechanism in which ECM contact is of key importance in regulating RPC cell cycle progression and the ensuing fate choice. 


\section{METHODS}

\section{Antibodies}

Phospho-Histone H3 (pSer28) (Sigma-Aldrich, Cat\# H9908 RRID:AB_260096), Ki67 (BD Pharmigen, Cat\# 550609), aDystroglycan blocking antibody (Ervasti et al., 1990; Ervasti and Campbell, 1991) Kevin Campbell, HHMI, University of Iowa, IIH6), $\beta$-1 Integrin blocking antibody (BD Biosciences, Cat\# 553715 RRID:AB_395001), IgM Isotype Control from murine myeloma (Sigma-Aldrich, Cat\# M5909 RRID: AB_1163655), Rat IgG2ak (BD Biosciences, Cat\# 559073 RRID:AB_479682).

\section{Chemicals, Peptides, and Recombinant Proteins}

EdU (Life Technologies, Cat\# C10337), Hoechst (Invitrogen, Cat\# H3570), Laminin-521 (BioLamina, Cat\# LN521-3), and Donkey Serum (Sigma-Aldrich, Cat\# D9663).

\section{Experimental Organisms}

C57Bl6/J Mice (Jackson Laboratories, Bar Harbor ME, United States, RRID:IMSR_JAX:000664), Lamb2 ${ }^{-/-}$Mice (Noakes et al., 1995).

\section{Software}

Volocity 3D Image Analysis Software (Perkin Elmer, RRID: SCR_002668, SCR_002668), Graphpad Prism (Graphpad, RRID:SCR_002798, SCR_002798).

\section{Experimental Model}

Deletion of the Lamb2 gene and production of the Lamb2 $2^{-/-}$mice have been described previously (Noakes et al., 1995). Lamb2 $2^{-/-}$ animals have been backcrossed to C57BL/6J over nine generations. Animals were maintained as heterozygotes. All animal procedures were performed in accordance with the Institutional Committee (IACUC) and the Institutional Biosafety Committee.

\section{Immunostaining}

The following primary antibodies were used: rat anti-phospho Histone H3 (1:3,000, Sigma-Aldrich, H9908), mouse anti-Ki67 (1:300, BD Pharmigen, Cat\# 550609). The following secondary antibodies were used: donkey anti-mouse 488 (1:300), donkey anti-rat 594 (1:500) (Life Technologies). Hoechst (1:100,000, Invitrogen, H3570) was used to stain cell nuclei. EdU was detected per vendor's instructions.

\section{Retinal Preparations}

Radial sections were prepared by making an incision in the ora serrata, fixing the eyes in $4 \%$ paraformaldehyde (PFA) for $15 \mathrm{~min}$, cryoprotected in $20 \%$ sucrose, and mounted in O.C.T. embedding medium. $12 \mu \mathrm{m}$ sections were collected on microscope slides with a cryostat. Sections were washed in PBS and then blocked for $30 \mathrm{~min}$ at room temperature in 5\% donkey serum in PBS with $0.3 \%$ Triton X-100. Following washing in PBS, sections were incubated with primary antibodies overnight at $4^{\circ} \mathrm{C}$ in $5 \%$ donkey serum in PBS with $0.01 \%$ Triton $\mathrm{X}-100$ (25 $\mu \mathrm{l}$ per section). Following washing in PBS, sections were incubated with secondary antibodies for $4 \mathrm{~h}$ at room temperature. Following incubation with secondary antibodies, sections were washed and mounted in Vectashield mounting medium (Vector Laboratories, $\mathrm{H}-1000)$ and imaged. To ensure comparable regions of the retina were analyzed, all sections used were oriented nasal-temporally and traversed the optic nerve. For flat-mount retinal preparations, eyes were enucleated and an incision was made in the ora serrata. The eye was then fixed in $4 \% \mathrm{PFA}$ in PBS at $4^{\circ} \mathrm{C}$ for $30 \mathrm{~min}$. The cornea and lens were then removed, and the sclera was peeled off. Four radial cuts were made to flatten the retina, which was then transferred to a well of a 24-well plate with PBS. After washing in PBS, retinas were incubated overnight at $4^{\circ} \mathrm{C}$ in blocking solution (5\% donkey serum in PBS with $0.3 \%$ Triton X-100). Next, retinas were incubated with primary antibodies in $300 \mu \mathrm{l}$ solution of $5 \%$ donkey serum in PBS with $0.01 \%$ Triton $\mathrm{X}-100$, at $4^{\circ} \mathrm{C}$ for $24 \mathrm{~h}$, washed, and incubated with secondary antibodies in same solution overnight. Following washing, tissues were mounted in ProLong ${ }^{\circledR}$ Gold Antifade Reagent (Life Technologies, P36930).

\section{Ex vivo Rescue and Receptor Blocking Experiments}

Organotypic retinal cultures with RPE intact were prepared as described previously (Serjanov et al., 2018). For rescue studies: following the medium change after first $24 \mathrm{~h}$ in culture, $10 \mu \mathrm{l}$ medium containing $50 \mathrm{pMol}$ laminin-521 was placed on the retinal surface. Medium containing no laminin was used as negative control. For receptor blocking studies: following the medium change, $10 \mu \mathrm{l}$ medium containing $1 \mathrm{nMol} \alpha$-DG blocking antibody or $500 \mathrm{pMol} \beta 1$-integrin blocking antibody or both was placed on the retinal surface. Nonspecific IgM and IgG2ak were used as isotype controls, respectively. After 3 days in vitro, cultures were fixed for flat-mounts or cryosections as described above.

\section{Cumulative S-phase EdU Labeling}

In vivo cumulative S-phase labeling was performed by administering intraperitoneal injections of EdU in sterile saline at $3 \mathrm{~h}$ intervals, up to $33 \mathrm{~h}$, at a dose of $100 \mathrm{mg} / \mathrm{kg}$. Mice were collected $30 \mathrm{~min}$ following the last injection, and retinal preparations were performed as described above. To ensure consistent result, and control for possible circadian changes of cell cycle dynamics, all mine were collected at $11 \mathrm{am}$ at P3. Ex vivo cumulative $S$-phase labeling was performed by adding medium containing $2 \mu \mathrm{M}$ EdU to the top and bottom compartments of the transwell inserts housing the retinal explants. The explants stayed in the labeling medium until being collected, for up to $21.5 \mathrm{~h}$, prior to being collected and analyzed. To ensure consistent result, and control for possible circadian changes of cell cycle dynamics, all explants were collected at 11am of 3DIV.

\section{Percentage of Labeled Mitoses Studies}

In vivo labeled mitoses studies were performed by administering a single intraperitoneal injection of EdU in sterile saline at a dose of 
$100 \mathrm{mg} / \mathrm{kg}$. Retinas were collected at intervals of $1,1.5,2$, and $2.5 \mathrm{~h}$ following the injection. To ensure consistent result, and control for possible circadian changes of cell cycle dynamics, every mouse was collected at $11 \mathrm{am}$ at P3. Ex vivo labeled mitoses studies were performed by adding medium containing $2 \mu \mathrm{M}$ EdU to the top and bottom compartments of the transwell inserts housing the retinal explants. The explants stayed in the labeling medium until being collected, $1,1.5,2$, and $2.5 \mathrm{~h}$ prior to being collected and analyzed. To ensure consistent result, and control for possible circadian changes of cell cycle dynamics, all explants were collected at $11 \mathrm{am}$ of $3 \mathrm{DIV}$.

\section{Analysis of Cell Cycle Parameters}

$\mathrm{T}_{\mathrm{C}}$ and $\mathrm{T}_{\mathrm{S}}$ calculations were done as follows. Labeling indices (LIs) for each cumulative label time point (from $\mathrm{LI}_{[0.5]}$ to $\mathrm{LI}_{[33.5]}$, reflecting the cumulative time of EdU labeling in hours) were calculated as a percentage of EdU+ cells within the neuroblastic layer (NBL) from $12 \mu \mathrm{m}$ retinal sections. This approach allows for a quantification of samples of varying size and thickness due to the data being normalized to the total number of cells within the NBL rather than the number of EdU+ cells alone. The data points were then plotted as LI vs time of cumulative label. $T_{C}$ and $T_{S}$ were calculated as described previously (Nowakowski et al., 1989), with modification. Briefly, the original method relies on assumption that LI increased linearly until reaching a plateau, while our data demonstrate that the saturation curve is clearly non-linear. A quadratic function was used to describe the LI rise phase instead. As there appeared to be two plateaus in the in vivo experiments, a combination of two quadratic functions, or a quartic function, was identified as the best-fit model. Growth fractions (GFs) were defined as the average of $\mathrm{LI}$ values lying on the plateau. $\mathrm{T}_{\mathrm{C}}-\mathrm{T}_{\mathrm{S}}$ points were determined mathematically by calculating the intercept between the cumulative labeling curve and the line defining GF.

$\mathrm{T}_{\mathrm{G} 2}$ and $\mathrm{T}_{\mathrm{M}}$ were determined as follows. The percentages of labeled mitoses were calculated from $12 \mu \mathrm{m}$ retinal cross-sections of samples collected at $1,1.5,2$, and $2.5 \mathrm{~h}$ after a single EdU injection, as percentages of $\mathrm{PH} 3+$ cells that were also EdU+. The data were then plotted as percentage of labeled mitoses vs time after EdU pulse. $\mathrm{T}_{\mathrm{G} 2}$ was calculated as the intersect of the abscissa and the line connecting the first two time points, as it reflects the time when $\mathrm{PH} 3+$ cells first start becoming EdU+. $\mathrm{T}_{\mathrm{M}}$ was calculated as the time when the line connecting the last two time points reached $100 \%$ label, as it reflects the time when EdU $+\mathrm{PH} 3+$ cells replace EdU-PH3+ cells.

$\mathrm{T}_{\mathrm{G} 1}$ was calculated by combining the data from the cumulative S-phase EdU labeling, and labeled mitoses studies, as the former allows calculation of $\mathrm{T}_{\mathrm{C}}$ and $\mathrm{T}_{\mathrm{S}}$, and the latter allows calculation of $\mathrm{T}_{\mathrm{G} 2}$ and $\mathrm{T}_{\mathrm{M}}$. The following formula was used: $\mathrm{T}_{\mathrm{G} 1}=\mathrm{T}_{\mathrm{C}}-\mathrm{T}_{\mathrm{S}}-\mathrm{T}_{\mathrm{G} 2}-\mathrm{T}_{\mathrm{M}}$.

\section{Experimental Design and Statistical Analysis}

Mice or retinal explants were collected following respective EdU course. Sex of the animals was not assessed. Retinal sections were imaged using OptiGrid structured illumination microscopy (Qioptiq Imaging Solutions, Advanced Imaging Concepts, Princeton NJ) from peripheral regions of three retinas per genotype or ex vivo condition per time point, on a Nikon Eclipse $\mathrm{Ni}$ microscope with $40 \mathrm{X}$ oil immersion, or $20 \mathrm{X}$ air objectives at room temperature. 60X oil immersion objective was used to obtain $0.2 \mu \mathrm{m}$-step $\mathrm{z}$ stacks of retinal flat-mounts for mitotic staging studies. All measurements were performed using Volocity (Perkin-Elmer, Waltham, MA, United States). Labeling indices, percentages of labeled mitoses, and mitosis staging counts were performed by manually counting cells of interest in retinal cross-sections. The data points were compared using Student's t-test (for two-condition comparison) or ANOVAs with Bonferroni's multiple comparisons test (three or more conditions). Data were represented as mean \pm S.E.M. Line slope comparisons were performed using ANCOVA. All statistical analyses and graphical representations were performed using GraphPad Prism 6.0. In figures, significances are represented as follows: ${ }^{\star} p \leq 0.05 ;{ }^{\star *} p \leq 0.01$; and ${ }^{\star * *} p \leq 0.001$. Adobe Illustrator CS3 and Adobe Photoshop CS3 were used for non-quantitative image editing and arrangement, such as image rotation and figure composition.

\section{RESULTS}

\section{RPC Cell Cycle Dynamics Are Laminin Dependent}

To determine whether RPC cell cycle progression is affected by the ILM composition, we examined the cell cycle dynamics using cumulative S-phase labeling with 5-ethynyl-2-deoxyuridine (EdU). P3 animals received consecutive intraperitoneal EdU injections at 3 -h intervals to sequentially label cells in the $\mathrm{S}$-phase, with an injection $30 \mathrm{~min}$ prior to tissue harvest (Figure 1A). Number of EdU+ cells within the neuroblastic layer $(\mathrm{NBL})$ increases with time, until reaching a plateau at the maximum labeling index (LI), allowing determination of the growth fraction ( $\mathrm{GF}$ - proliferating cell population relative to total cells in the tissue). Studying the increase and saturation of EdU+ population allows determination of lengths of the cell cycle $\left(\mathrm{T}_{\mathrm{C}}\right)$ as well as the S-phase $\left(\mathrm{T}_{\mathrm{S}}\right)$ (Figure 1B) (Nowakowski et al., 1989). LIs for each time point were calculated as percentages of EdU+ nuclei in the NBL (Figure 1C). Curiously, the saturation curves for both WT and Lamb2 $2^{-/-}$retinas displayed a clear biphasic shape, with two rise-phases and plateaus, suggesting distinct waves of cell cycle exit and re-entry (Figure 1D). While the GFs were not different between the WT and Lamb2 ${ }^{-/-}$, the $\mathrm{LI}_{[0.5]}$ (LI in mice that received a single EdU injection $30 \mathrm{~min}$ prior to tissue harvest) was significantly reduced in the $L a m b 2^{-/-}$ retinas. This suggests that there is a decreased proportion of RPCs in S-phase at a given time in $L a m b 2^{-1-}$ retinas. Calculation of $\mathrm{T}_{\mathrm{C}}$ and $\mathrm{T}_{\mathrm{S}}$ resulted in values of 42.6 and $24.4 \mathrm{~h}$ for $\mathrm{WT}$, and 29.3 and $11.5 \mathrm{~h}$ for $\mathrm{Lamb2}^{-/-}$retinas, respectively. The calculated WT values are similar to the ones previously reported (Alexiades and Cepko, 1996). These data suggest that Lamb2 deletion results in shortening of the S-phase and the cell cycle in general. It is noteworthy that a previous study demonstrated S-phase shortened in RG and IPCs undergoing neurogenic divisions, compared to proliferative divisions (Arai et al., 2011). Together, these data are consistent with our previous report 
A

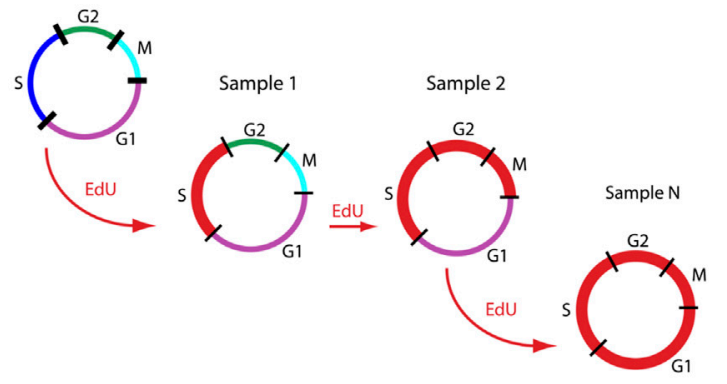

B

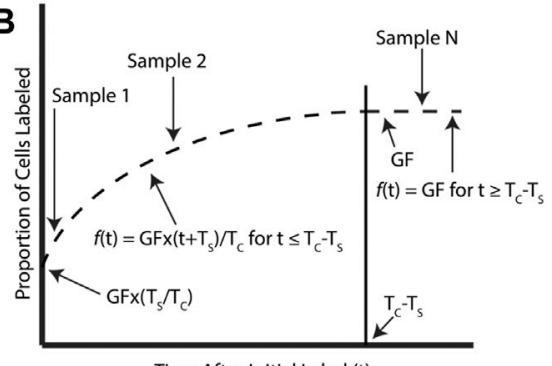

Time After Initial Label (t)

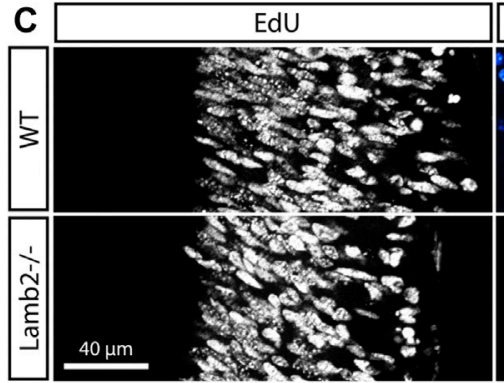

D

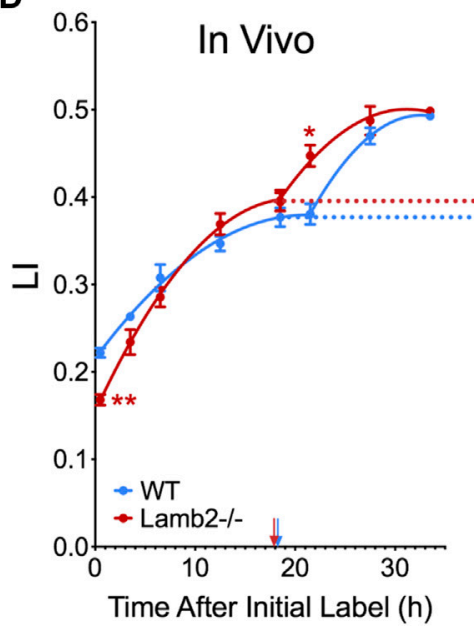

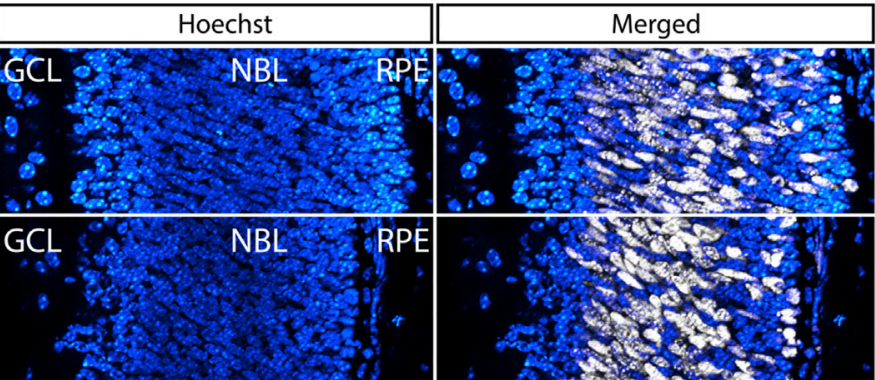

E

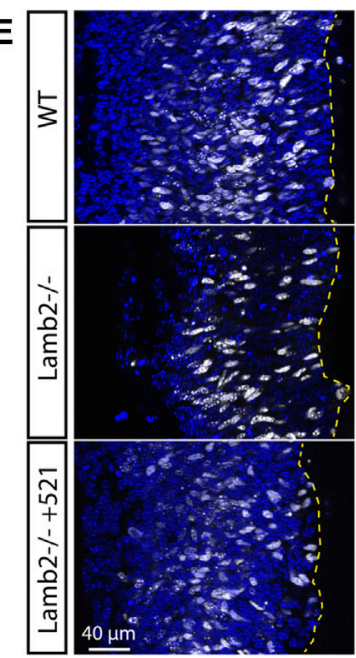

F

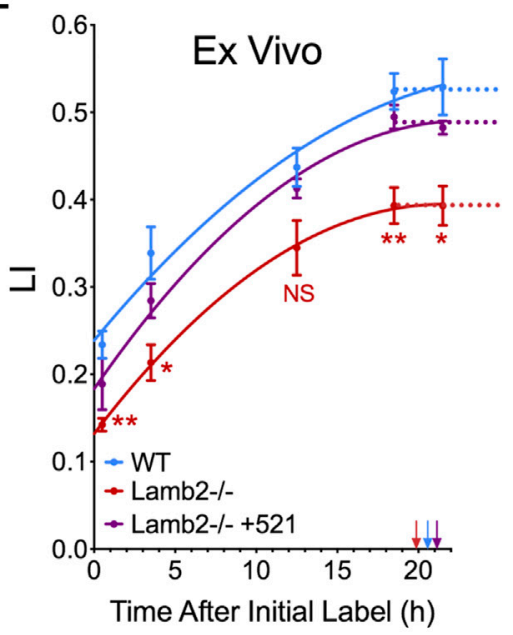

FIGURE 1 | RPC $T_{C}$ and $T_{S}$ are laminin-dependent. (A). Model illustrating the principle of cumulative S-phase labeling. This method relies on continuous EdU exposure, labeling successive populations of cells entering the S-phase. Red line marks the distribution of EdU-labeled cells within the cell cycle. (B). Model illustrating the quantification of the results of cumulative EdU labeling. The proportion of EdU+ cells within the NBL was measured and plotted vs. the time off EdU exposure. A sharp initial rise in the labeling index reflects entry of unlabeled cells into the S-phase. This is followed by a plateau, which indicates the time when the entire proliferating population has been labeled. Growth fraction (GF) is measured as the ratio of EdU+ cells to total cell number in the NBL. TC-time of cell cycle. TS-time of the S-phase. (C). Representative images of cross-sections of P3 retina that had been continuously labeled for $27.5 \mathrm{~h}$. (D). EdU saturation curves resulting from cumulative EdU labeling experiments in P3 retinas. (E). Representative images of cross-sections of retinal explants that had been continuously labeled for $21.5 \mathrm{~h}$. (F). EdU saturation curves resulting from cumulative EdU labeling experiments performed on retinal explants. Dotted lines designate the GF at plateaus in the curves. Arrows indicate time when labeling index reached the plateau $\left(T_{C}-T_{S}\right)$.

that Lamb2 deletion results in a shift of multipotent RPCs towards fate-restricted rod progenitors (Serjanov et al., 2018).

\section{Exogenous Laminin $\beta 2$ Rescues RPC Cell Cycle and S-phase Timing}

To confirm our findings and to test whether $\beta 2$-containing laminins at the ILM directly affect RPC cell cycle dynamics, we performed cumulative EdU labeling studies ex vivo. Retinal explants were prepared from P0 eyes, and grown in the top compartment of transwells, with the retinal pigmented epithelium (RPE) intact, ganglion cell layer up. After 1 day in vitro (DIV), a droplet of medium containing recombinant laminin 521 (trimer containing $\alpha-5, \beta-2$, and $\gamma-1$ chains) was added to the retinal surface. In so doing, laminin $\beta 2$ is introduced into the retina as a functional trimer. Medium without recombinant laminin was used as a control. Rescue by exogeneous addition of laminin in vitro has been previously used to great success (Li et al., 2002; Gnanaguru et al., 
A EdU Pulse Labels Cells in S Phase EdU-Labels Cells Progress From S Into G2 and M
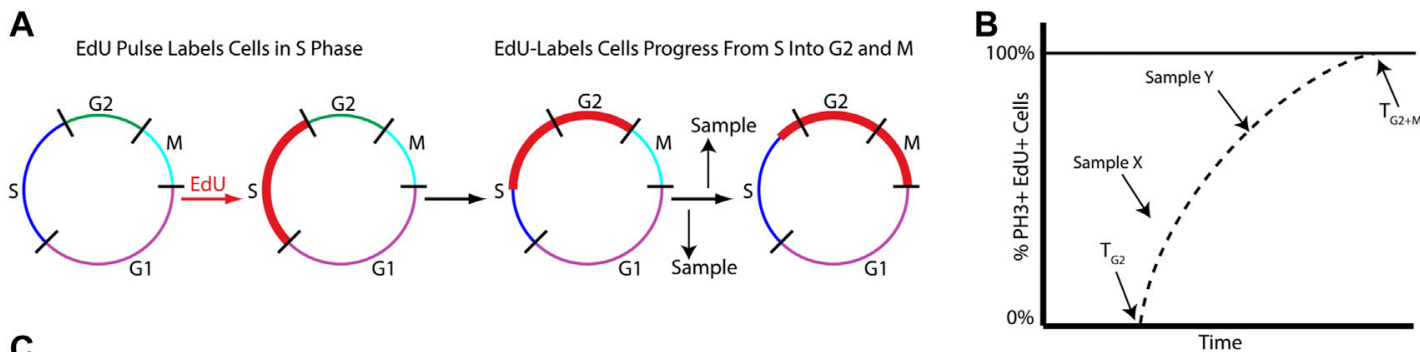

C

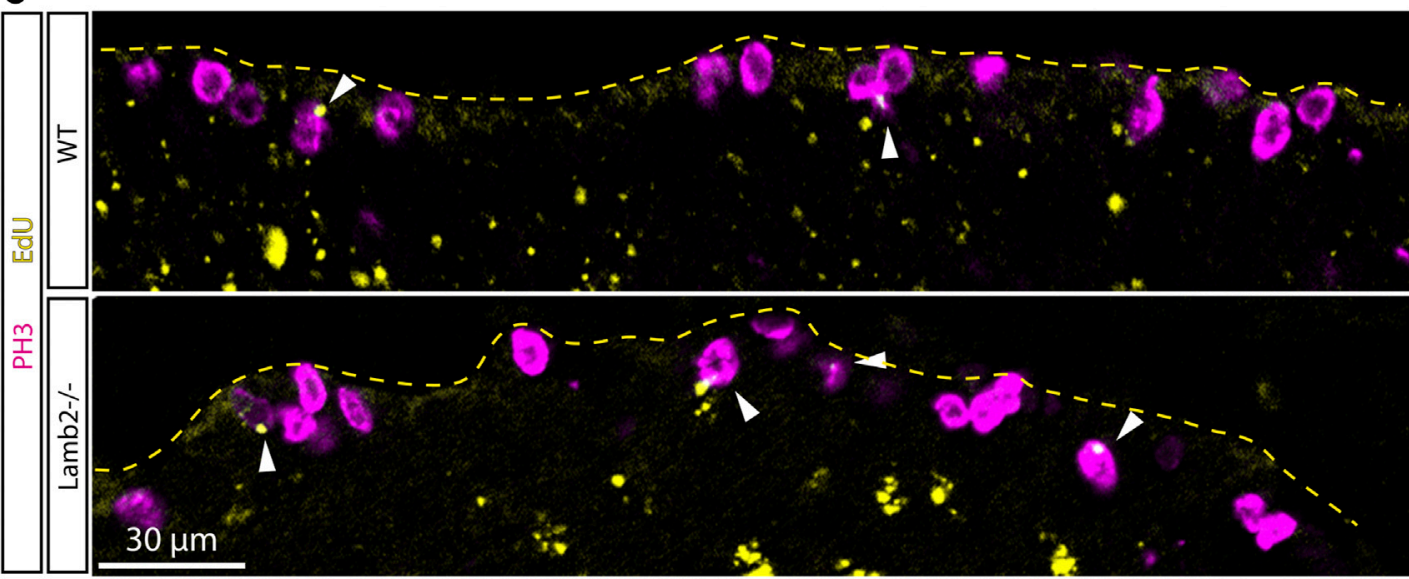

D

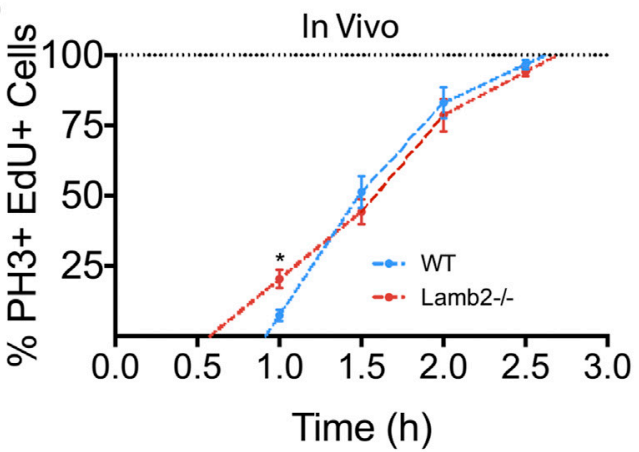

$\mathbf{E}$

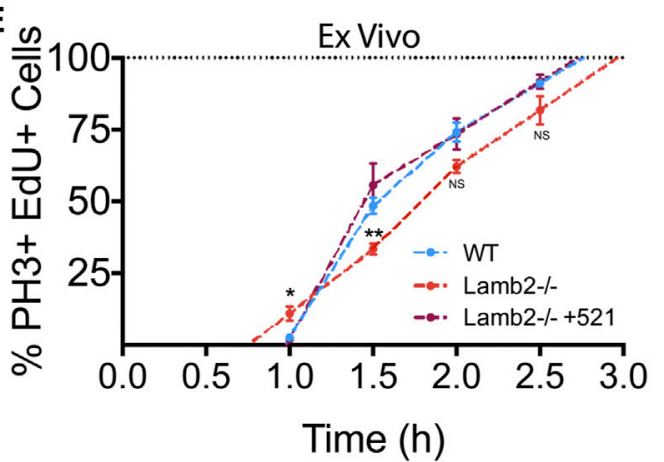

FIGURE 2|RPC G2/M progression is laminin-dependent. (A). Model representation of the principles of the percentage of labeled mitosis method. This procedure relies on a brief EdU exposure of proliferating cells. Tracking the dynamics of mitotic entry of EdU+ cells (red), allows determining the time it takes to go from S to M-phase. (B). Model illustrating the quantification of the labeled mitosis experiments. The time of G2 ( $\left.T_{G 2}\right)$ is determined as the time needed for EdU+ cells to enter mitosis (become $\mathrm{PH}+$ ). Time of mitosis $\left(\mathrm{T}_{\mathrm{M}}\right)$ is calculated as the time required for EdU+/PH3+ population to replace EdU-/PH3+ population. (C). Representative images of labeled mitosis experiments performed at P3, and collected $1 \mathrm{~h}$ after EdU injection. Dashed line indicates the apical surface of the retina. Arrowheads indicate EdU+/PH3+ cells, marking RPCs that have gone from S, into M-phase within $1 \mathrm{~h}$. (D). In vivo percentage of labeled mitosis saturation graphs of P3 retinas. Lamb2 ${ }^{-/-}$retinas present faster rate of M-phase entry and delayed initial mitotic progression, compared to WT. (E). Ex vivo percentage of labeled mitosis saturation graphs of retinal explants. Lamb2 ${ }^{-/-}$ explants present faster rate of M-phase entry and delayed initial mitotic progression, similar to in vivo results. Each data point represents the average of technical and biological experimental replicates \pm SEM. Statistical analysis was performed using Student's t-test. ${ }^{\star}-p \leq 0.05$. ${ }^{\star \star}-p \leq 0.01$. NS - not significant.

2013; Serjanov et al., 2018). Following that, culture medium containing $2 \mu \mathrm{M}$ EdU was used to replace half the volume of the bottom compartment, as well as added to the top compartment at times ranging from 0.5 to $21.5 \mathrm{~h}$ prior to tissue fixation at $3 \mathrm{DIV}$. Analysis of the resulting saturation curves revealed a decrease in GF in Lamb2 $2^{-1-}$ explants compared to the WT. Addition of laminin 521 to the surface of the $L a m b 2^{-/-}$cultures rescued this phenotype (Figure 1E). Calculation of $\mathrm{T}_{\mathrm{C}}$ and $\mathrm{T}_{\mathrm{S}}$ resulted in values of 36.5 and 16.0 for WT; 30.1 and 10.3 for $L a m b 2^{-1-}$; and 37.4 and $16.3 \mathrm{~h}$ for $\mathrm{Lamb2}^{-/-}+521$, respectively. Together, these data demonstrate that the presence of $\beta 2$-containing laminins at the retinal surface is necessary for proper timing of the cell cycle and the S-phase.

\section{RPC G2/M Progression Is Laminin-dependent}

To further investigate the effects of $\beta 2$-containing laminins on RPC cell cycle dynamics, we examined the timing of G2 and M phases using the percent of labeled mitoses approach (Quastler and Sherman, 1959). To examine the G2/M dynamics, P3 mice were injected with EdU, and retinas were collected at 1, 1.5, 2, and $2.5 \mathrm{~h}$ 

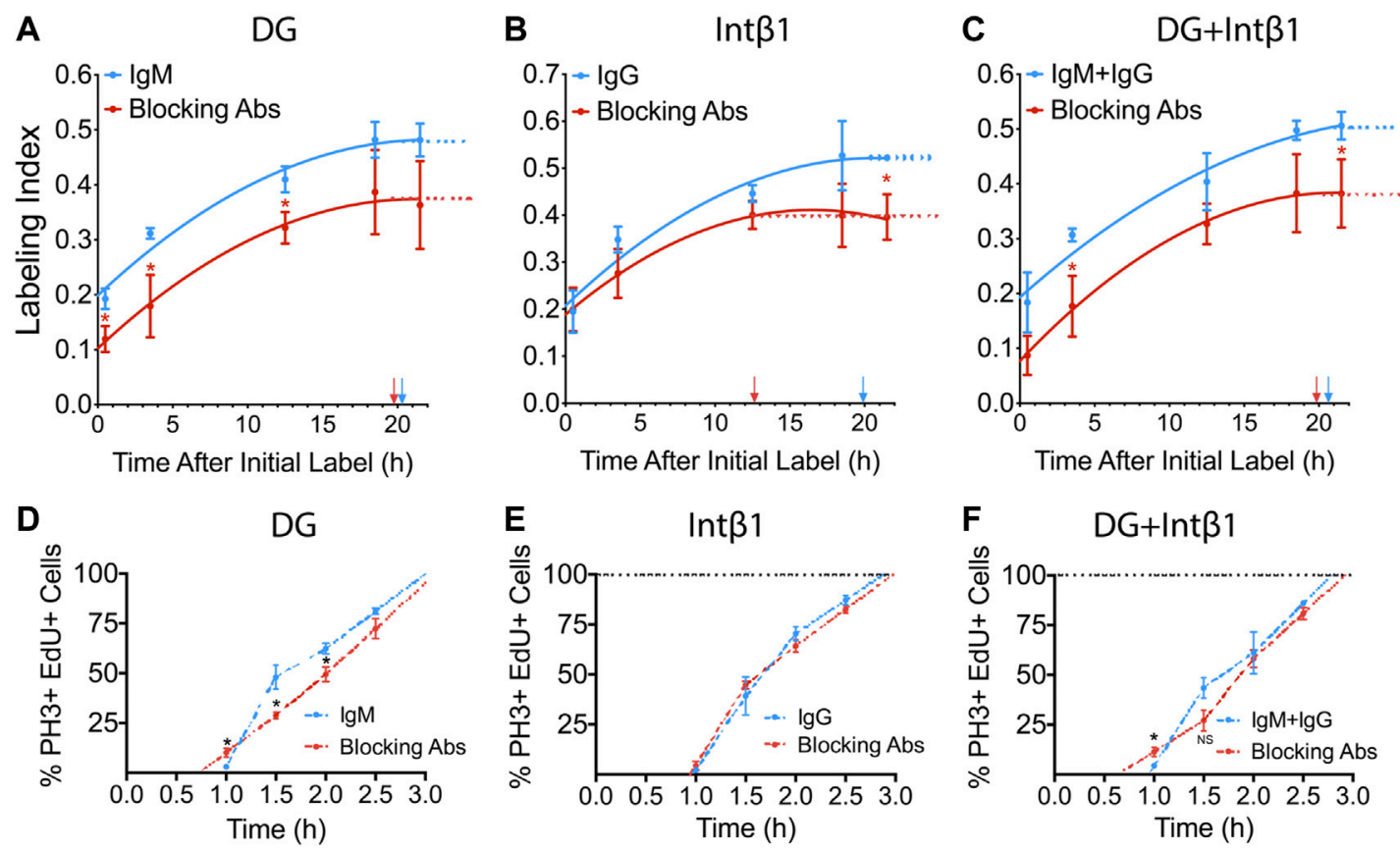

FIGURE 3 | DG and intB1 regulate RPC cell cycle dynamics. (A). Cumulative S-phase EdU labeling graphs of WT retinal explants with a-DG blocking antibodies. (B). Cumulative S-phase EdU labeling graphs of WT retinal explants with int $\beta 1$ blocking antibodies. (C). Cumulative S-phase EdU labeling graphs of WT retinal explants with $\alpha$-DG and int $\beta 1$ blocking antibodies. Arrows indicate $T_{C}-T_{S}$. (D). Labeled mitoses graphs for WT retinal explants with $\alpha$-DG blocking antibodies. (E). Labeled mitoses graphs for WT retinal explants with int $\beta 1$ blocking antibodies. (F). Labeled mitoses graphs for WT retinal explants with a-DG and intB1 blocking antibodies. Each data point represents the average of technical and biological experimental replicates \pm SEM. Statistical analysis was performed using Student's t-test. ${ }^{\star}-p \leq 0.05$. NS- not significant.

intervals to assess the EdU saturation of mitotic cells labeled with anti-phospho-Histone $\mathrm{H}_{3}^{\mathrm{Ser} 28}(\mathrm{PH} 3)$ antibodies. (Figure 2A). Observing the dynamics of EdU saturation of the $\mathrm{PH} 3+$ population allowed calculation of lengths of $\mathrm{G} 2\left(\mathrm{~T}_{\mathrm{G} 2}\right)$, as determined by the time needed for EdU+ cells to become $\mathrm{PH} 3+$, reflecting time needed for cells to go from $S$ to $M$ phases; and $M$ $\left(\mathrm{T}_{\mathrm{M}}\right)$, as quantified by the time between EdU+ cells becoming $\mathrm{PH} 3+$ and all $\mathrm{PH} 3+$ cells becoming EdU+, reflecting the time needed for EdU + cells to replace all EdU- mitotic cells (Figure 2B). Inspection of $\mathrm{PH} 3+\mathrm{RPCs}$ revealed an increased number of mitotic EdU + RPCs 1 hour after EdU injection in $\mathrm{Lamb2}^{-/-}$retinas relative to the WT (Figure 2C). Analysis of later time points revealed a slower initial rate of EdU saturation in Lamb2 ${ }^{-/-}$retinas, as determined by comparing the slopes of the lines connecting the one and $1.5 \mathrm{~h}$ time points, while the later phase was unaffected (Figure 2D). Our WT $\mathrm{EdU}+/ \mathrm{PH} 3+$ saturation values closely resemble those reported previously (Pacal and Bremner, 2012). Analysis of the mitotic EdU saturation dynamics allowed calculation of $\mathrm{T}_{\mathrm{G} 2}$ and $\mathrm{T}_{\mathrm{M}}$, which were 0.9 and $1.7 \mathrm{~h}$ for $\mathrm{WT}$; and 0.6 and $2.1 \mathrm{~h}$ for $\mathrm{Lamb2}^{-/-}$, respectively. These data suggest that Lamb2 deletion results in accelerated G2 and prolonged $\mathrm{M}$ in the RPCs.

\section{Exogenous Laminin $\beta 2$ Rescues RPC G2 and $M$ Phase Progression}

To confirm our findings and to test whether $\beta 2$-containing laminins at the ILM directly affect RPC G2/M progression, we performed the percent of labeled mitosis studies ex vivo. Retinal explants were prepared as described above, but the EdUcontaining medium was added to the top chamber of the transwells containing the retinal explants at $1,1.5,2$, or $2.5 \mathrm{~h}$ prior to tissue collection. Similar to our in vivo findings, $\mathrm{Lamb2}^{-/-}$ cultures displayed accelerated G2 and delayed M progression, with slower initial EdU+/PH3+ saturation rate as compared to WT explants. Addition of laminin 521 to the surface of Lamb2 $2^{-1-}$ retinal explants rescued G2/M dynamics (Figure 2E). Analysis of the mitotic EdU saturation revealed $\mathrm{T}_{\mathrm{G} 2}$ and $\mathrm{T}_{\mathrm{M}}$ to be 1.0 and $1.8 \mathrm{~h}$ for WT; 0.8 and $2.2 \mathrm{~h}$ for Lamb2 ${ }^{-1-}$; and 1.0 and $1.7 \mathrm{~h}$ for Lamb2 ${ }^{-1-}+521$ cultures, respectively. Together these data demonstrate that the presence of $\beta 2$-containing laminins at the retinal surface is necessary for proper timing of the G2 and $\mathrm{M}$ phases in RPCs.

\section{2-Containing Laminins Modulates RPC Cell Cycle Dynamics via Dystroglycan}

We have previously reported that Lamb2 deletion results in RPC basal process retraction, leading to disruption of ECM-RPC contact and mislocalization of its receptors-DG and int $\beta 1$, and that their proper localization is restored by addition of laminin 521 ex vivo (Serjanov et al., 2018). Thus, we proceeded to investigate the role of these receptors in transducing the signals that regulate the cell cycle progression, from the ECM to the RPCs. To do so, we performed a series of ex 
TABLE 1 | In vivo and ex vivo RPC cell cycle parameters.

\begin{tabular}{|c|c|c|c|c|c|c|c|c|}
\hline & \multicolumn{8}{|c|}{ In Vivo } \\
\hline & $\mathbf{T}_{\mathrm{C}}$ & $\mathbf{T}_{\mathrm{G} 1}$ & \multicolumn{2}{|c|}{$\mathbf{T}_{\mathbf{S}}$} & $\mathrm{T}_{\mathrm{G} 2}$ & $T_{M}$ & $\mathbf{G F} \pm \mathbf{S D}$ & $T_{C^{-}}-T_{S}$ \\
\hline WT & 42.6 & 15.5 & \multicolumn{2}{|c|}{24.4} & \multicolumn{2}{|c|}{1.7} & $37.9 \pm 1.7 \%$ & 18.2 \\
\hline \multirow[t]{3}{*}{ Lamb2 $^{-/-}$} & 29.3 & 15.2 & \multicolumn{2}{|c|}{11.5} & \multicolumn{2}{|c|}{2.1} & $39.6 \pm 2.1 \%$ & 17.9 \\
\hline & & \multicolumn{7}{|c|}{ Ex Vivo } \\
\hline & & $\mathbf{T}_{\mathrm{c}}$ & $\mathbf{T}_{\mathrm{G1}}$ & $\mathbf{T}_{\mathbf{S}}$ & $\mathbf{T}_{\mathrm{G} 2}$ & $\mathbf{T}_{\mathbf{M}}$ & $\mathbf{G F} \pm \mathbf{S D}$ & $T_{C}-T_{S}$ \\
\hline \multicolumn{2}{|l|}{ WT } & 36.5 & 17.8 & 16.0 & 1.0 & 1.8 & $52.6 \pm 4.2 \%$ & 20.6 \\
\hline \multicolumn{2}{|l|}{ Lamb2 $^{-/-}$} & 30.1 & 16.9 & 10.3 & 0.8 & 2.2 & $39.3 \pm 3.4 \%$ & 19.9 \\
\hline \multicolumn{2}{|c|}{ Lamb2 $^{-/-}+521$} & 37.4 & 18.4 & 16.3 & 1.0 & 1.7 & $48.9 \pm 1.8 \%$ & 21.1 \\
\hline \multirow{2}{*}{\multicolumn{2}{|c|}{$\begin{array}{l}\text { Control lgM } \\
\text { a-DG }\end{array}$}} & 34.6 & 17.5 & 14.3 & 1.0 & 2.0 & $48.0 \pm 2.8 \%$ & 20.3 \\
\hline & & 27.2 & 16.8 & 7.5 & 0.7 & 2.4 & $37.3 \pm 6.9 \%$ & 19.7 \\
\hline \multirow{2}{*}{\multicolumn{2}{|c|}{$\begin{array}{l}\text { Control lgG } \\
\text { IntB1 }\end{array}$}} & 33.0 & 17.1 & 13.1 & 0.97 & 1.9 & $52.1 \pm 4.7 \%$ & 19.9 \\
\hline & & 23.9 & 9.6 & 11.3 & 0.95 & 2.0 & $39.9 \pm 5.2 \%$ & 12.6 \\
\hline \multirow{2}{*}{\multicolumn{2}{|c|}{$\begin{array}{l}\text { Control lgM + lgG } \\
\alpha-D G+\ln B 1\end{array}$}} & 33.5 & 17.8 & 12.9 & 0.9 & 1.8 & $50.2 \pm 2.0 \%$ & 20.6 \\
\hline & & 24.8 & 16.8 & 5.0 & 0.6 & 2.3 & $38.3 \pm 5.7 \%$ & 19.8 \\
\hline
\end{tabular}

Cell cycle parameters were calculated from the data in Figures $1 D, E, 2 D, E, 3 A-F$.

Times shown in hours. $T_{C}$, time of cell cycle, $T_{G 1}$, time of G1, $T_{S}$, time of $S, T_{G 2}$, time of G2, $T_{M}$, time of $M$.

vivo cumulative EdU labeling experiments. WT retinal cultures were prepared as described above, with an additional step of applying either $\alpha$-DG (IIH6) or int $\beta 1$ (9EG7) function-blocking antibodies to the retinal surface. Blocking $\alpha-D G$ signaling resulted in reduction of both $\mathrm{LI}_{[0.5]}$ as well as the GF, relative to control antibodies (Figure 3A), and similar to the Lamb2 $2^{-1-}$ (Figure 1E). The resulting $\mathrm{T}_{\mathrm{C}}$ and $\mathrm{T}_{\mathrm{S}}$ values were 34.6 and $14.3 \mathrm{~h}$ for the control antibody cultures, and 27.2 and $7.5 \mathrm{~h}$ for the $\alpha-\mathrm{DG}$ blocking cultures, respectively. Blocking int $\beta 1$ signaling did not affect $\mathrm{LI}_{[0.5]}$, but decreased the GF as well as the time needed to reach the saturation plateau (Figure 3B). The resulting $\mathrm{T}_{\mathrm{C}}$ and $\mathrm{T}_{\mathrm{S}}$ values were 33.0 and $13.1 \mathrm{~h}$ for the control antibody cultures, and 23.9 and $11.3 \mathrm{~h}$ for the int $\beta 1$ blocking cultures, respectively. Blocking both receptors resulted in a curve similar to one obtained from $\alpha$-DG, without int $\beta 1$-block features (Figure $3 \mathrm{C}$ ). The resulting $\mathrm{T}_{\mathrm{C}}$ and $\mathrm{T}_{\mathrm{S}}$ values were 33.5 and $12.9 \mathrm{~h}$ for the control antibody cultures, and 24.8 and $5.0 \mathrm{~h}$ for the compound blocking cultures, respectively. These data suggest that the shortening of $\mathrm{T}_{\mathrm{C}}$ and $\mathrm{T}_{\mathrm{S}}$ observed in $\mathrm{Lamb2}^{-/-} \mathrm{RPCs}$ are due to impaired DG-mediated signaling.

To further assess the roles of the laminin receptors in controlling cell cycle dynamics, we performed a series of labeled mitoses studies in retinal explants that were treated with $\alpha-D G$ or int $\beta 1$ blocking antibodies. Similar to the mitosis labeling dynamics observed in $\mathrm{Lamb2}^{-/-}$cultures (Figure 2E), $\alpha$ DG blocking resulted in accelerated mitotic entry, and slower initial progression through mitosis (Figure 3D). Analysis of the mitotic EdU saturation revealed $\mathrm{T}_{\mathrm{G} 2}$ and $\mathrm{T}_{\mathrm{M}}$ to be 1.0 and $2.0 \mathrm{~h}$ in control cultures, and 0.7 and $2.4 \mathrm{~h}$ in $\alpha$-DG block cultures, respectively. Int $\beta 1$ blocking did not have an effect on mitosis labeling relative to the control (Figure $3 \mathrm{E}$ ). Analysis of the mitotic EdU saturation revealed $\mathrm{T}_{\mathrm{G} 2}$ and $\mathrm{T}_{\mathrm{M}}$ to be 0.97 and $1.9 \mathrm{~h}$ in control cultures, and 0.95 and $2.0 \mathrm{~h}$ in int $\beta 1$ blocked cultures, respectively. Compound block of both $\alpha-D G$ and int $\beta 1$ resulted in accelerated mitotic entry and delayed initial progression, similar to blocking a-DG alone (Figure 3F). Analysis of the mitotic EdU saturation revealed $\mathrm{T}_{\mathrm{G} 2}$ and $\mathrm{T}_{\mathrm{M}}$ to be 0.9 and $1.8 \mathrm{~h}$ for the control cultures, and 0.6 and $2.3 \mathrm{~h}$ for the compound block cultures, respectively. Together these data demonstrate that DG-mediated signaling controls cell cycle dynamics in RPCs, independently of $\operatorname{int} \beta 1$.

Combining all the data from both in vivo and ex vivo studies, we were able to calculate the lengths of $\mathrm{G} 1\left(\mathrm{~T}_{\mathrm{G} 1}\right)$ for each condition by simple arithmetic: $T_{G 1}=T_{C^{-}} T_{S^{-}} T_{G 2}-T_{M}$. The resulting $\mathrm{T}_{\mathrm{G} 1}$ values reveal no effect on $\mathrm{T}_{\mathrm{G} 1}$ in $L a m b 2^{-/-}$, or a-DG blocked conditions, while showing that it was considerably decreased in int $\beta 1$ blocked conditions. Complete cell cycle dynamics are summarized in Table 1. Taken together, these data suggest that $\beta 2$-containing laminins regulate RPC cell cycle progression through DG-mediated signaling.

\section{RPC S-phase Progression Is Laminin-dependent by DG Pathway}

Having observed a shortening of the S-phase in $L a m b 2^{-/-}$retinas, we proceeded to further investigate the effects of $\beta 2$-containing laminins on dynamics of the S-phase progression. Eukaryotic nuclei contain over $10^{4}$ replication domains (Hand, 1978). In early S-phase, hundreds of these domains are active and distributed throughout the nucleoplasm, while only tens are active in late S-phase (Manders et al., 1992; 1996). This allows for an easy identification of cells in early vs late stages. Thymidine analogue labeling of newly synthesized DNA of cells in early S-phase appears as largely uniform staining, composed of hundreds of small labeled domains scattered throughout the nucleoplasm, while late S-phase replicons appear much larger in size and fewer in number, both in vitro as well as in vivo (Manders et al., 1992; Manders et al., 1996; Jaunin et al., 1998; Ma et al., 1998; Yamada et al., 2005). We used this cytological feature to assess whether Lamb2 deletion affects RPC S-phase progression in addition to duration. P3 retinas were collected 1 hour after a single EdU injection, and analyzed in cross sections (Figure 4A). Consistent with the literature, RPC nuclei in early and late S-phases were easily discernable. EdU labeling of early S-phase nuclei was largely uniform throughout the nucleoplasm, while the late S-phase nuclei presented a small number of large EdU+ puncta (Figure 4B). Additionally, the positioning of the EdU+ RPCs was consistent with the interkinetic nuclear migration, where early S-phase cells were located basally, while the late S-phase cells were located apically (Figure 4A). Analysis of the EdU labeling revealed a significant increase in late S-phase RPCs in $\mathrm{Lamb2}^{-/-}$retinas (Figure 4C). These findings suggest that Lamb2 deletion causes an increase in RPCs residing in late stages of S-phase.

To test whether the observed increase in late S-phase RPCs is directly due to the loss of $\beta 2$-containing laminins at the retinal surface, we performed ex vivo rescue studies, and analyzed early to late S-phase ratios. As culture system cannot clear EdU, medium containing $2 \mu \mathrm{m}$ EdU was added to the top transwell compartment $30 \mathrm{~min}$ prior to fixation, rather than $1 \mathrm{~h}$, as was done in vivo, to prevent continuous labeling, which may alter the 

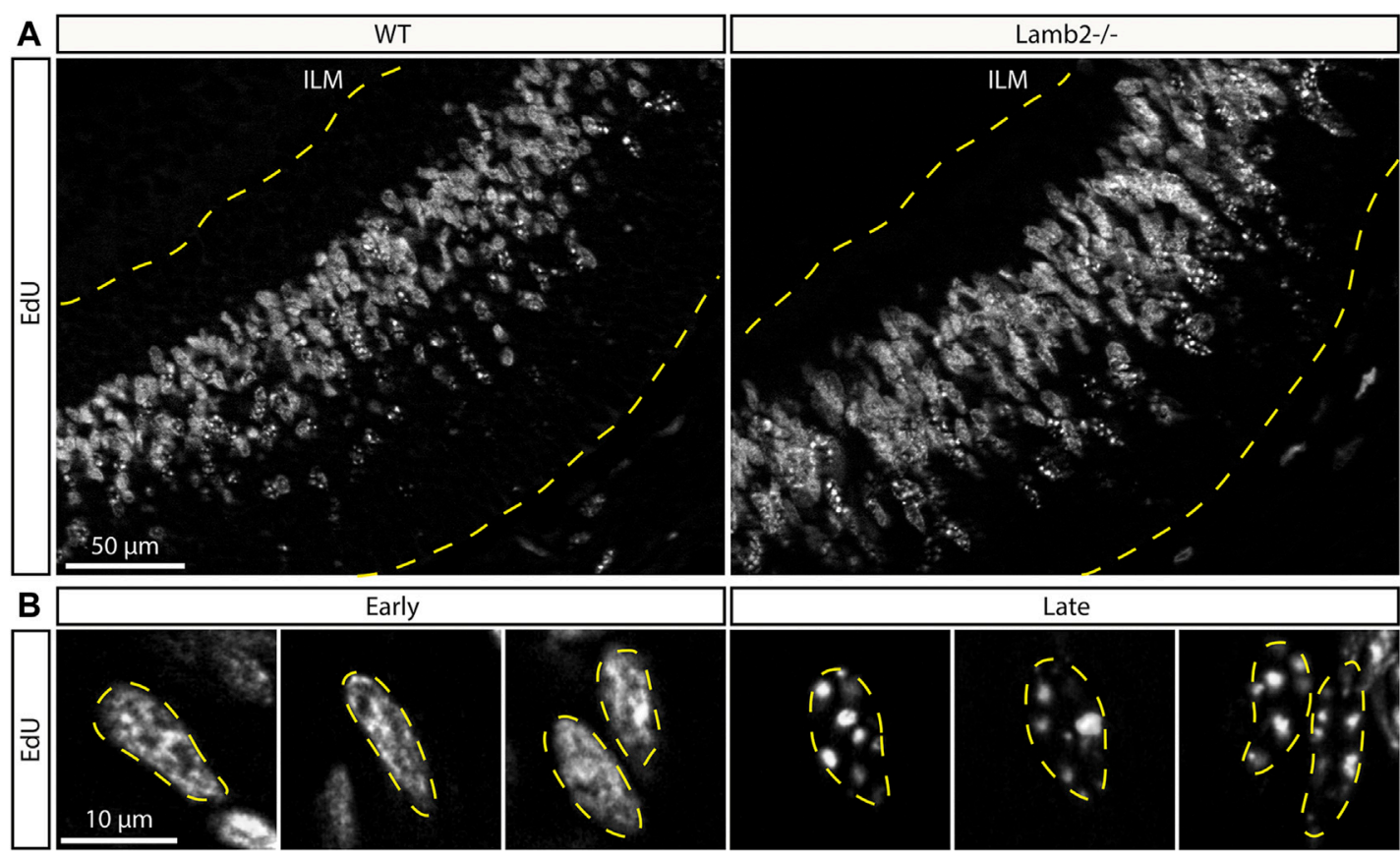

C In Vivo
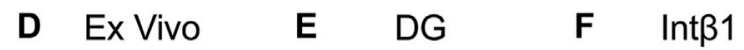

G DG + Int $\beta 1$
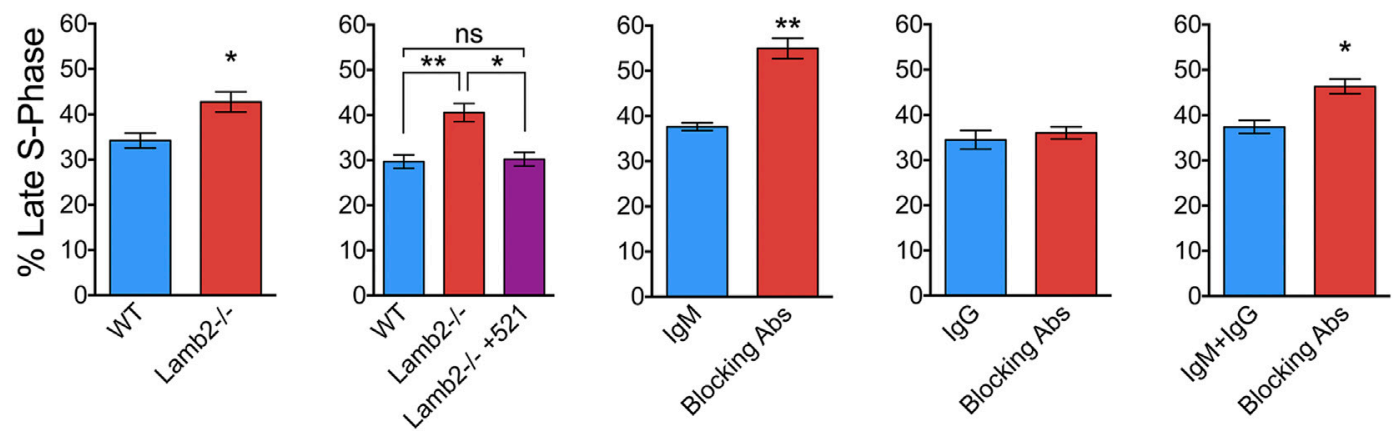

FIGURE 4 | 32 -containing laminins regulate RPC S-phase progression via DG. (A). EdU labeling in P3 retinal cross-sections. Dashed lines delineate the retinal tissue limits. ILM-inner limiting membrane. (B). High power representative images of RPCs in early (left) and late (right) S-phases. Replicon activity is reflected in pattern of EdU incorporation. Early S-phase is characterized by high number of active replicons, leading to a uniform EdU incorporation. Late S-phase is characterized by low number of active replicons, leading to punctate EdU incorporation. (C). Quantification of RPCs in late S-phase relative to RPCs in all stages of S-phase in P3 WT and Lamb2 $^{-/-}$cross-sections. Lamb2 ${ }^{-/-}$RPCs display higher percentage of cells in late S-phase relative to WT. (D). Quantification of RPCs in late S-phase in retinal explants. Lamb2 $^{-/}$explants display higher percentage of late S-phase cells, compared to WT. Addition of laminin 521 rescues this effect, restoring normal early/late S-phase ratios. (E). Quantification of RPCs in late S-phase in WT retinal explants with and without $\alpha$-DG blocking antibodies. Blocking $\alpha$-DG signaling results in increased percentage of late S-phase RPCs. (F). Quantification of RPCs in late S-phase in WT retinal explants with and without int $\beta 1$ blocking antibodies. Blocking int $\beta 1$ signaling has no effect on percentage of late S-phase RPCs. (G). Quantification of RPCs in late S-phase in WT retinal explants with and without a combination of $\alpha$-DG and int $\beta 1$ blocking antibodies. Blocking both signaling pathways results in increased percentage of late S-phase RPCs. Each data point represents the average of technical and biological experimental replicates \pm SEM. Statistical analysis was performed using Student's t-test. ${ }^{\star}-p \leq 0.05$. ${ }^{\star \star}-p \leq 0.01$. NS - not significant.

results. Similar to the in vivo results, the percentage of late S-phase RPCs was significantly increased in Lamb2 ${ }^{-/-}$explants compared to WT. Addition of laminin 521 rescued this effect and restored the early-to-late S-phase ratios to WT levels (Figure 4D). Together, these data demonstrate that $\beta 2$-containing laminins at the retinas surface directly affect RPC S-phase progression.

Following these results, we proceeded to investigate whether DG was responsible for mediating the ECM-RPC signaling that regulates the $\mathrm{S}$-phase progression, in addition to duration. As a-DG blocking phenocopies the Lamb2 ${ }^{-/-}$cell cycle dynamics (Table 1), we hypothesized that it would also affect the S-phase dynamics in the same way Lamb2 deletion does. Indeed, blocking $a-D G$ in retinal explants resulted in a significant increase of late S-phase RPCs (Figure 4E), while int $\beta 1$ blocking had no effect (Figure 4F). Compound blocking of both receptors resulted in an increase of late S-phase RPCs as well, though not as pronounced as a-DG block alone (Figure 4G). Taken together, these data demonstrate the 

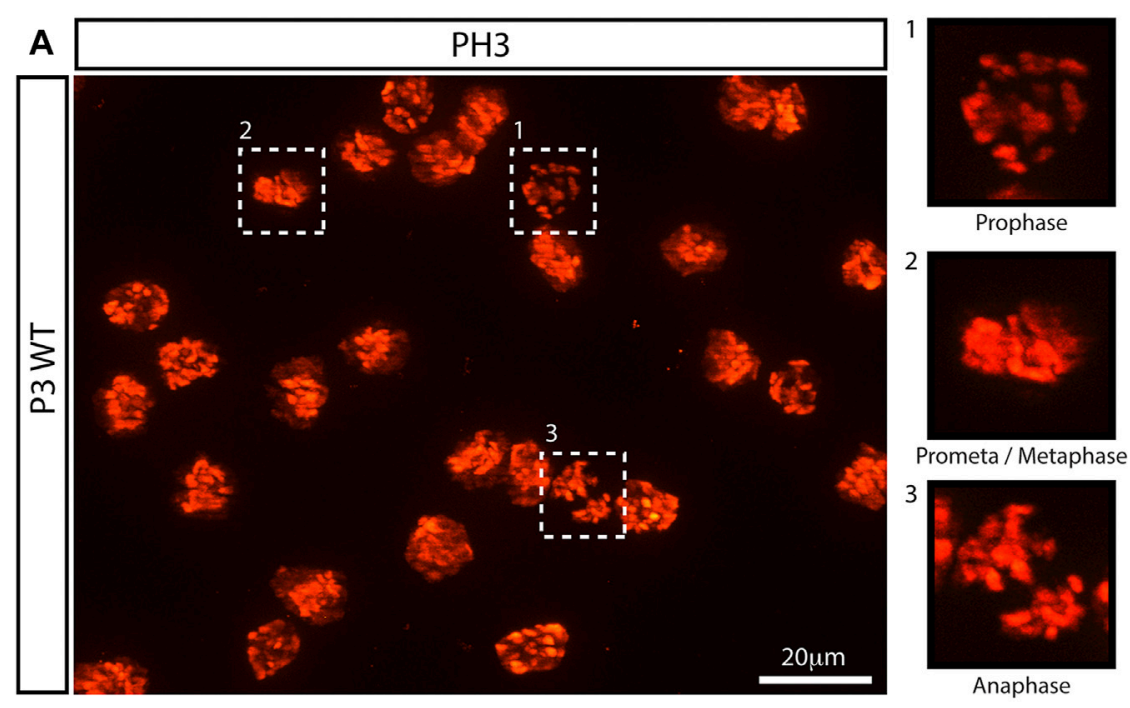

C

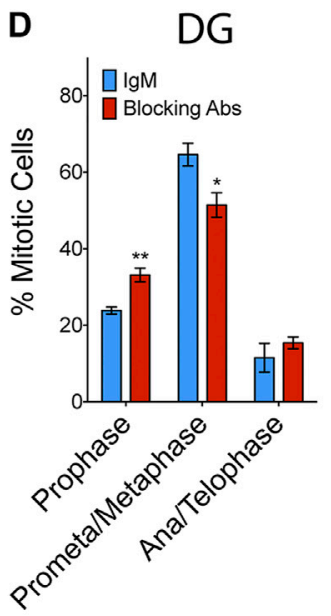

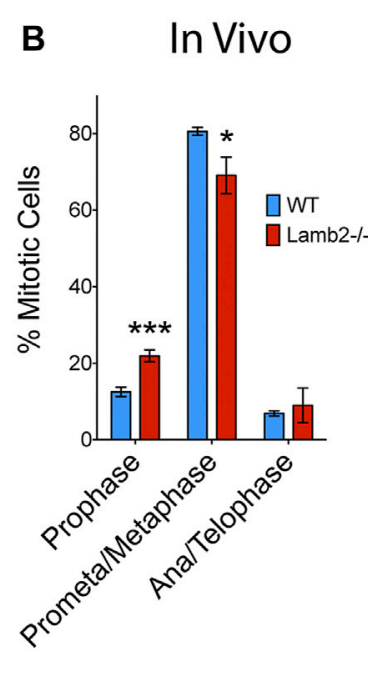

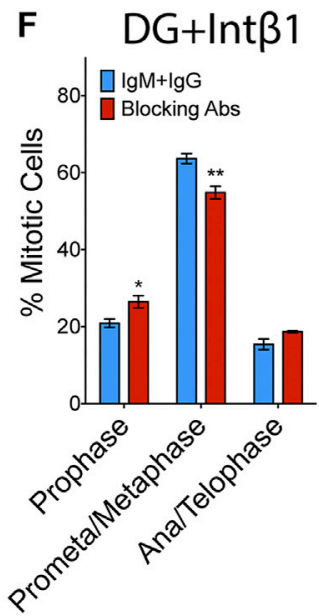

FIGURE 5 | $\beta 2$-containing laminins regulate RPC M-phase progression via DG. (A). Extended focus view of a z stack obtained from the apical surface of a retinal flat-mount. As PH3 is associated with condensed chromatin, it allows for mitotic staging, based on its staining pattern within the cell. (B). Quantification of RPCs in various stages of mitosis in WT and Lamb2 ${ }^{-/-}$retinas. Lamb2 ${ }^{-/}$retinas display higher relative percentages of RPCs in prophase with a concomitant decrease of ones in prometa/metaphase, compared to WT. (C). Quantification of RPCs in various stages of mitosis in WT and Lamb2 ${ }^{-/-}$retinal explants. Lamb2 ${ }^{-/-}$explants display higher relative percentages of RPCs in prophase with a concomitant decrease of ones in prometa/metaphase, similar to in vivo results. Addition of laminin 521 to Lamb2 $^{-/-}$explants rescues normal mitosis stage ratios. (D). Quantification of RPCs in various stages of mitosis in WT retinal explants with and without $a$-DG blocking antibodies. Blocking $\alpha$-DG signaling results in higher relative percentages of RPCs in prophase with a concomitant decrease of ones in prometa/metaphase, relative to control. (E). Quantification of RPCs in various stages of mitosis in WT retinal explants with and without intB1 blocking antibodies. Blocking int $\beta 1$ signaling has no effect on mitotic stage distribution of RPCs. (F). Quantification of RPCs in various stages of mitosis in WT retinal explants with and without a compound $\alpha-D G / i n t \beta 1$ blockade. Blocking both signaling pathways results in higher relative percentages of RPCs in prophase with a concomitant decrease of ones in prometa/metaphase, similar to Lamb2 $^{-/-}$and WT $+\alpha-D G$ block. Each data point represents the average of technical and biological experimental replicates \pm SEM. Statistical analysis was performed using Student's t-test. ${ }^{\star}-p \leq 0.05 .{ }^{\star \star}-p \leq 0.01$. ${ }^{\star \star \star}-p \leq 0.001$. NS - not significant.

RPC S-phase dynamics are laminin-dependent and regulated by DG.

\section{RPC Mitosis Progression Is Laminin-dependent and Modulated by DG}

Cell fate choice of the RG in the developing cortex is known to be affected by the length of mitosis as well as its progression dynamics. Previous study reported that cells dwelling for an extended period in prometaphase have an increased propensity to produce postmitotic or apoptotic daughter cells (Pilaz et al., 2016). We have observed an extended M-phase duration (Table 1) and an apparent initial delay in mitotic progression in $\mathrm{Lamb2}^{-/-}$RPCs (Figures 2D,E). We, therefore, proceeded to investigate whether the M-phase dynamics are affected by $\beta 2$ containing laminins. Mitotic RPCs were visualized in retinal flatmounts using $\mathrm{PH} 3$. Mitosis phases were inferred from the $\mathrm{PH} 3$ staining pattern obtained from $\mathrm{z}$-stacks of the retinal apical 

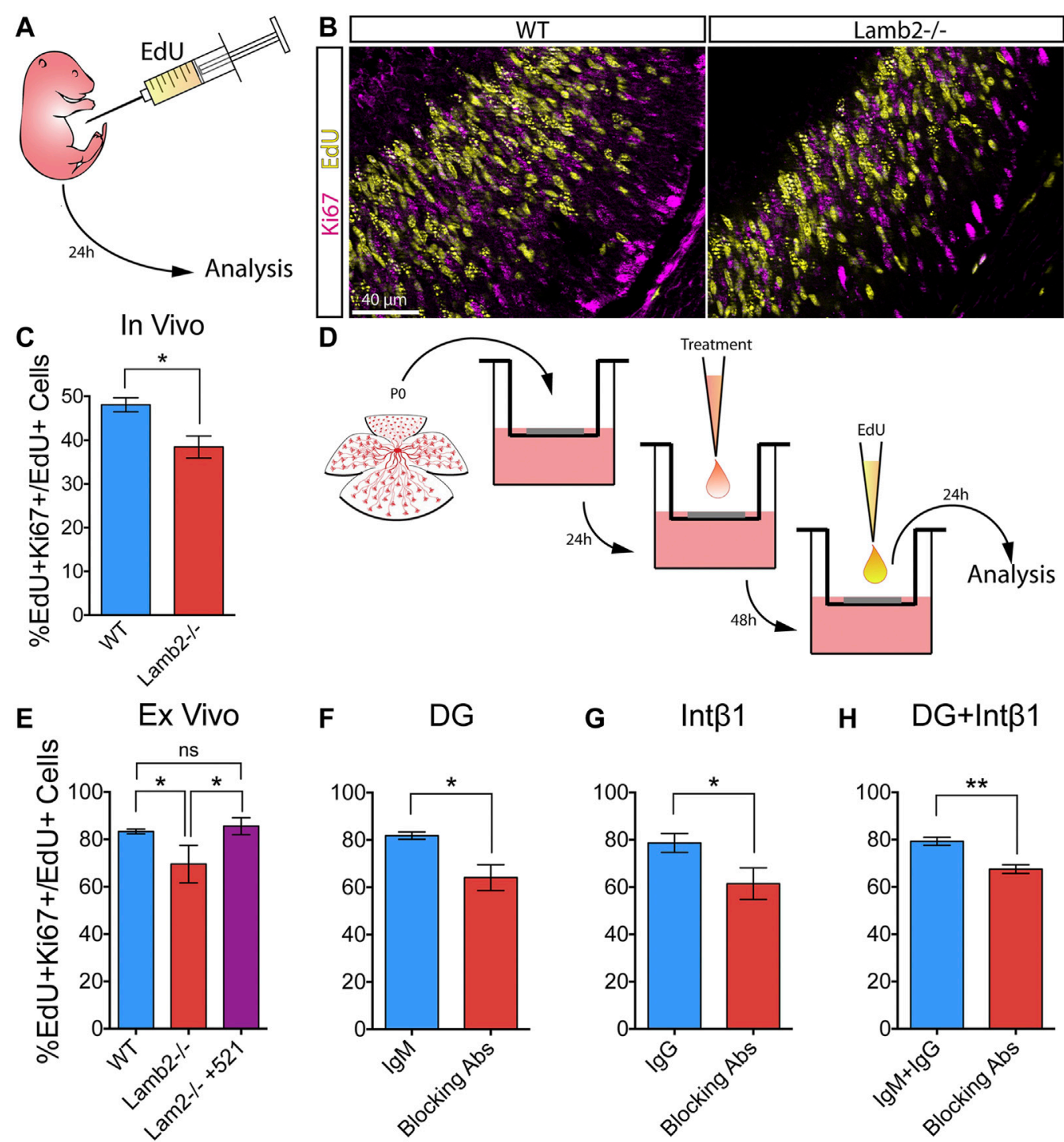
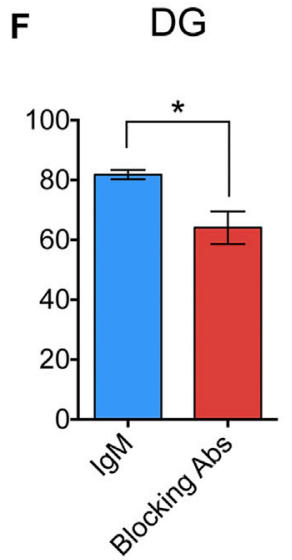

G

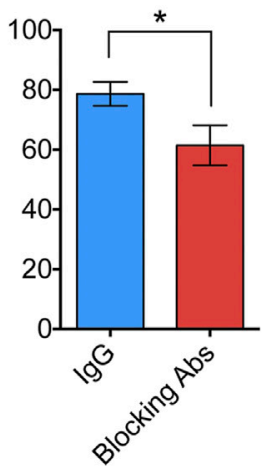

H $\quad$ DG+ $+\operatorname{lnt} \beta 1$

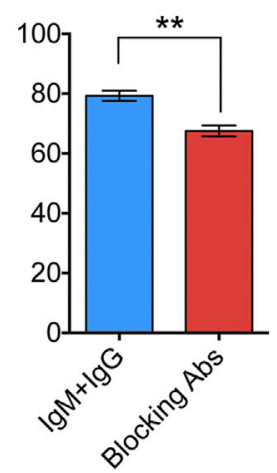

FIGURE 6 | $\beta 2$-containing laminins regulate RPC cell cycle re-entry via DG and int $\beta 1$. (A). Experimental paradigm for determining the rate of RPC cell cycle reentry. P3 mice were administered a single intraperitoneal EdU injection, and their retinas were collected $24 \mathrm{~h}$ later. The resultant retinal cross-sections were then stained for EdU (proliferating RPCs at P3) and Ki67 (proliferating RPCs at P4) to assess the rate of RPC cell cycle re-entry. (B). Representative images of P4 retinal cross-sections stained for EdU and Ki67. (C). Quantification of EdU/Ki67 stained retinas. EdU+Ki67 + RPCs (RPCs that have re-entered the cell cycle) were significantly decreased in Lamb2 $^{-/-}$retinas, compared to WT. (D). Experimental paradigm for determining the rate of RPC cell cycle reentry in retinal explants. Explants were prepared from P0 retinas and grown ganglion cell layer up in transwells. After $24 \mathrm{~h}$, a drop of medium containing either laminin 521, function-blocking antibodies, or control antibodies, was added to the retinal surface. After 48h, medium containing EdU was added to the top compartment, and the retinas were collected $24 \mathrm{~h}$ later. The resultant crosssections were then stained for EdU and Ki67. (E). Quantification of EdU/Ki67 stained retinal explants. EdU+Ki67 + RPCs (RPCs that have re-entered the cell cycle) were significantly decreased in Lamb2 ${ }^{-/-}$explants, compared to WT. Addition of laminin 521 to Lamb2 ${ }^{-/-}$explants restored normal cell cycle re-entry. (F). Blocking a-DG signaling in WT retinal explants significantly reduced the rate of RPC cell cycle re-entry. (G). Blocking int $\beta 1$ signaling in WT retinal explants significantly reduced the rate of RPC cell cycle re-entry. (H). Blocking both $\alpha-D G$ and int $\beta 1$ signaling in WT retinal explants significantly reduced the rate of RPC cell cycle re-entry. Each data point represents the average of technical and biological experimental replicates \pm SEM. Statistical analysis was performed using Student's t-test. * $-p \leq 0.05$. ${ }^{\star \star}-p \leq 0.01$. NS- not significant.

surface (Figure 5A). As Histone $\mathrm{H} 3$ phosphorylation is associated with chromosome condensation and segregation (Rossetto et al., 2012), PH3 staining provides a useful tool in determining the mitotic state of the cell. In prophase, when chromosomes begin to condense, PH3 appears discontinuous and punctate, reflecting the state of chromatin condensation (Figures 5A-1). In prometaphase, the chromosomes become fully condensed, and
PH3 labels the chromosomes entirely. The chromosomes then align at the metaphase plate during metaphase (Figures 5A-2). At anaphase, the chromosomes segregate towards the opposing mitotic spindle poles (Figures 5A-3). During late anaphase, Histone H3 becomes dephosphorylated by PP1 due to chromosome decondensation, and can be observed in late anaphase/telophase as faint staining surrounding the chromosomes (not shown). Analysis of the 
mitotic RPCs in P3 retinas revealed a significant increase in the number of cells in prophase with a concomitant significant decrease in the prometa/metaphase population, in $\mathrm{Lamb2}^{-/-}$retinas. The late-M population was unaffected (Figure 5B). These data are consistent with $\mathrm{EdU} / \mathrm{PH} 3$ saturation dynamics, where the initial mitosis progression is significantly slower, while the late stage is unaffected (Figure 2D).

To confirm that the prophase extension is directly affected by $\beta 2$-containing laminins at the retinal surface, we performed ex vivo rescue studies. Analysis of the flat-mounted retinal explants revealed a significant increase in prophase and a significant decrease in prometa/metaphase, without affecting the late-M populations, in $\mathrm{Lamb2}^{-/-}$cultures. Addition of laminin 521 to $\mathrm{Lamb2}^{-/-}$retinas restored the normal M-phase dynamics. These data are consistent with the EdU/PH3 saturation dynamics described above (Figure 2E). Together these data demonstrate the direct link between the $\beta 2$-containing laminins in the ECM and mitosis dynamics in the RPCs.

To further investigate the molecular mechanisms governing the regulation of RPC mitosis dynamics, we performed a series of ex vivo receptor blocking studies to elucidate the roles of laminin receptors in this pathway. $\alpha-D G$ blocking resulted in a significant increase in the prophase population, with a concomitant decrease in prometa/metaphase population. The late-M population was not affected (Figure 5D). Int $\beta 1$ blocking did not change mitosis dynamics (Figure 5E). Compount $\alpha-D G$ and int $\beta 1$ blocking resulted in a significant increase in the prophase population, with a concomitant decrease in prometa/metaphase population, similar to $\alpha$-DG-only block. The late-M population was not affected (Figure 5F). These data are in agreement with the results of EdU/PH3 saturation studies described above (Figures 3D-F). Together, these data demonstrate that the M-phase dynamics are laminin-dependent, and mediated by the DG signaling pathway.

\section{RPC Cell Cycle Re-entry Is Laminin Dependent}

Having observed altered cell cycle dynamics in $\mathrm{Lamb2}^{-/-}$retinas, we proceeded to investigate whether the observed changes affected the RPC self-renewal. P3 mice were administered a single intraperitoneal EdU injection, and the retinas were collected $24 \mathrm{~h}$ later (Figure 6A). Retinal cross-sections were then stained for EdU and Ki67, to detect RPCs that were proliferating at $\mathrm{P} 3$ and those proliferating at $\mathrm{P} 4$, respectively (Figure 6B). As Ki67 is expressed from late G1 to the end of M (Pacal and Bremner, 2012), it provides a useful tool for discriminating between EdU+ cells that have re-entered, or exited the cell cycle. Analysis of the percentage of EdU+ cells that were also Ki67+ revealed a significant decrease of the doublelabeled RPC population in $L a m b 2^{-/-}$retinas compared to WT (Figure 6C).

To confirm that increased RPC cell cycle exit is the direct result of lack of $\beta 2$-containing laminins at the retinal surface, we performed a series of ex vivo rescue studies. Medium containing $2 \mu \mathrm{M}$ EdU was added to the top transwell compartment of 3DIV retinal explants, and the tissues were collected $24 \mathrm{~h}$ later, at $4 \mathrm{DIV}$ (Figure 6D). Similar to the in vivo results, Lamb2 $2^{-/}$explants exhibited a significant decrease of the EdU+Ki67+ population compared to WT. Addition of laminin 521 rescued this effect (Figure 6E). Together, these results demonstrate that RPC cell cycle re-entry is directly affected by $\beta 2$-containing laminins at the retinal surface.

\section{DG and int $\beta 1$ Modulate RPC Cell Cycle Re-entry}

Having established the role of $\beta 2$-containing laminins in regulating RPC cell cycle re-entry and exit, we proceeded to examine the roles of DG and int $\beta 1$ in mediating this effect. Using the ex vivo approach, we assessed RPC cell cycle re-entry following receptor blockade. Blocking either $\alpha-D G$ or int $\beta 1$ resulted in a significant decrease of the EdU+/Ki67+ population compared to control (Figures 6F,G). Combining the two treatments also resulted in a significant decrease in RPC cell cycle re-entry. These effects did not appear to be additive, as compound blocking of both receptors did not result in a significantly greater effect than either receptor blocking alone (Figure 6H). These data suggest that DG and int $\beta 1$ mediated signaling pathways are involved in the regulation of RPC proliferation in rather complex fashion (see discussion for further comments).

\section{DISCUSSION}

Recent progress in understanding of the ECM functions in development has greatly expanded our appreciation of the importance of the complex microenvironment in which developmental processes take place. While ECM has been shown to play important roles in multiple processes on both cellular and tissue levels, its effects on cell cycle dynamics have remained largely unexplored. Here, we have identified the molecular signaling mechanism by which $\beta 2$ containing laminins regulate RPC cell cycle dynamics and, as a result, the choice between RPCs producing proliferating or post-mitotic progeny. We have established that 1) laminindependent signaling is involved in the regulation of the RPC cell cycle dynamics; 2) DG-mediated signaling is responsible for mediating the laminin-RPC signaling responsible for control of the cell cycle dynamics; 3) laminin-DG signaling is responsible for proper S-phase progression; 4) laminin-DG signaling is responsible for proper M-phase progression. Figure 7 presents a schematic summary of these findings. The role of ECM in modulating RPC cell cycle dynamics has wide reaching implications not only in the field of developmental biology, but in pathobiology as well, shedding light on basic cellular processes.

\section{Laminins Guide Proper RPC Cell Cycle Dynamics}

Numerous studies have noted the existence of a relationship between the cell cycle dynamics and progenitor cell fate determination. The initial reports noted that lengthening of 


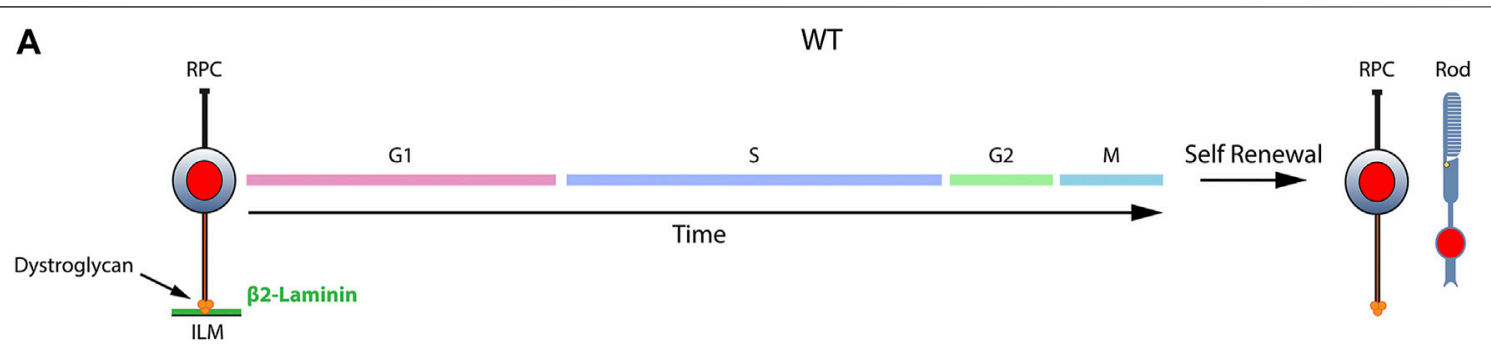

B

Lamb2-/-

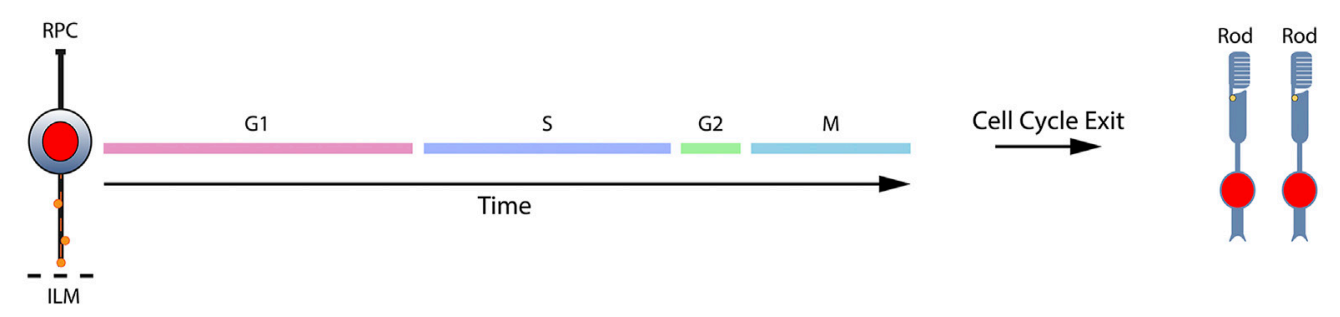

FIGURE 7 | $\beta 2$-containing laminins govern RPC proliferation by modulating the cell cycle dynamics via DG. Contact between RPCs and the ILM is maintained throughout the cell cycle via a variety of receptors. The signaling cascades modulated by these receptors play important roles in controlling the cell cycle dynamics and the ensuing cell fate. (A). DG mediates the signaling between RPCs and $\beta 2$-containing laminins in the ILM. Cells progress through cell cycle and proceed to divide in a self-renewing fashion, maintaining proper progenitor pool, or exit the cell cycle to produce retinal neurons. (B). Loss of laminin $\beta 2$ leads to disrupted ILM, which fails to provide proper binding sites to DG. This leads to mislocalization of the receptor and alters its molecular signaling pathways. As a result, RPC cell cycle dynamics are altered, and the resulting mitoses lead to premature cell cycle exit with overproduction of rods and premature progenitor pool depletion.

G1 is associated with increased cortical neurogenesis (Calegari, 2003; Calegari, 2005; Pilaz et al., 2009). Further studies of the neurogenesis dynamics revealed G1-extension to be specifically associated with the IPCs, which are biased towards more neurogenic than proliferative divisions (Arai et al., 2011). Additionally, both RG and IPCs undergo a notably shorter S-phase in the cell cycle preceding terminal division (Arai et al., 2011). More recent studies demonstrated detrimental effects of prolonged M-phase on progenitor self-renewal (Pilaz et al., 2016). While changes in cell cycle dynamics during tissue histogenesis are well known to have profound effects on differentiation, the underlying mechanisms regulating these changes remain to be determined. Our current findings suggest that laminins in the ILM provide essential signaling cues that regulate RPC cell cycle progression.

The effects of Lamb2 deletion of cell cycle dynamics and rate of mitotic exit reveal the importance of proper $3 \mathrm{D}$ microenvironment in development and morphogenesis. Our analysis of the cell cycle in $\mathrm{Lamb2}^{-/-}$provides further insight into the relationship between cell cycle and neurogenesis in the retina. Consistent with previous reports, we observed a reduced S-phase (Arai et al., 2011), and prolonged mitosis durations (Pilaz et al., 2016), accompanied by increased rate of cell cycle exit in $\mathrm{Lamb2}^{-/-}$retinas. Prolonged M-phase has been observed in lissencephaly and microcephaly models (Pilaz et al., 2016; Bershteyn et al., 2017). These findings are consistent with studies performed in zebrafish microcephaly models. RPCs of stil and odf2-deficient zebrafish embryos display prometaphase progression defects, followed by cell cycle exit or apoptosis (Novorol et al., 2013). These findings correlate with reports that both Lamb2-and DG-deficient mice also present cortical dysplasias (Moore et al., 2002; Satz et al., 2010; Radner et al., 2012).

Interestingly, our analysis of the prolonged M-phase dynamics differs from those reported previously. Reduced duration of prophase, and extended duration of prometa/metaphase has been observed in RG leaving cell cycle (Pilaz et al., 2016). We, on the other hand, observed increased numbers of RPCs in prophase, and reduction of those in prometa/metaphase in $L a m b 2^{-/-}$retinas. This difference in observations may be due to methodology. Studies describing prometaphase lengthening rely on live imaging of cortical slices, where mitosis stages are inferred from the appearance of the dividing cells. As such, live imaging in tissue is not reliable in distinguishing between late G2 and prophase. Our method, instead, relies on a molecular marker (PH3) that reflects the state of chromosome condensation, allowing for greater precision in determining the exact stage. Alternatively, it is possible that both observations are correct and describe differences in $\mathrm{M}$-phase progression between different conditions and tissues. Accelerated G2, followed by prolonged prophase had been previously described in models with aberrant Cyclin A/CDK2 activity, and was proposed to be related to premature condensation of incompletely replicated DNA (Furuno et al., 1999). This raises the possibility that the overall length of mitosis, rather than that of its specific phases, is important in regulating cell fate. It has recently been proposed that cells with prolonged M-phase are deemed as "problematic" and removed from the cell cycle (Pilaz et al., 2016). Interestingly, altered prophase/prometaphase/metaphase dynamics have also been noted in cancer (Therman et al., 1984), suggesting that 
proper M-phase progression plays a role not only in development, but pathogenesis as well. Taken together with our current observations, all these findings suggest that prolonged mitosis is a common feature of limited progenitor self-renewal throughout the CNS both in development and pathology, and underlines the importance of DG-mediated ECM signaling in development.

\section{Distinct Roles of DG and int $\beta 1$ Signaling in Cell Cycle Regulation}

We have previously reported that disruption of both DG and int $\beta 1$ signaling decreased RPC proliferation in a non-additive fashion (Serjanov et al., 2018). Consistent with those observations, our current study found that blocking $\alpha-D G$ or int $\beta 1$ in WT retinal explants decreased the progenitor pool and increased the rate of cell cycle exit, with the effects not appearing to be additive. Moreover, analysis of the cell cycle revealed completely different effects of either condition on its dynamics. While DG blocking results in shortening of $S$ and G2-phases, with an extension of $M$, int $\beta 1$ blocking only shortened G1. Combination of both treatments mimics the cell cycle dynamics of DG block without any of the effects of int $\beta 1$ blockade. This suggests that the two receptors have distinct signaling pathways in regulation of the cell cycle, with DG being the main transducer of ECM-RPC signaling. This idea is corroborated by the fact that cell cycle dynamics of DG block phenocopy those of $L a m b 2^{-/-}$retinas, while int $\beta 1$ blocking does not.

Interestingly, while int $\beta 1$ blocking causes shortening of the G1-phase, there is still a significant increase in the rate of cell cycle exit. Previous studies noted that forced reduction of G1phase duration by overexpression of cyclins D1 and E1 promoted cell cycle re-entry and reduced differentiation in the developing cortex (Pilaz et al., 2009). Our data suggest that the relationship between cell cycle dynamics and the ensuing cell cycle exit or re-entry decision is more complex than a straightforward length-dictates-fate scenario, and may be context-dependent. An alternative explanation could be that int $\beta 1$ blockade causes $\mathrm{G} 1$ arrest in a subpopulation of RPCs. As cumulative S-phase labeling method relies on cells continuously entering the S-phase, G1 arrest would prevent this from happening, thus making this population inaccessible to EdU label. This, however, is unlikely as $\mathrm{LI}_{[0.5]}$, which describes the ratio of cells in S-phase at any given time, is unaffected by int $\beta 1$ blockade, suggesting no defect in G1-S transition. Further investigation into the interplay between DG and int $\beta 1$, and their molecular signaling pathways in cell cycle regulation is required to shed more light on these processes.

It should be noted that there is a similarity between our observations of laminin-DG dependent regulation of the mitotic spindle (Serjanov et al., 2018) and the data presented here. Our observations of disrupted S-phase dynamics in DGblocked retinal explants may in part explain the alterations in the behavior of the RPC centrosomes as centrosomal replication also occurs during the S-phase and disruptions of one have an effect on the other (Stearns, 2001; Sluder and Nordberg, 2004; Sluder, 2005; Kuriyama et al., 2007; Acilan and Saunders, 2008). Interestingly, in both cases ECM-int $\beta 1$ mediated signaling has a distinctly different effect on RPC proliferation and maintenance than does DG-mediated signaling. Also, in both cases of regulation of the mitotic spindle orientation as well as of the cell cycle, DGmediated signaling appears to be the dominant pathway, as demonstrated by DG-block phenotype in DG+int $\beta 1$ retinal cultures. A similar dichotomy was seen between integrin and DG signaling in early embryonic development (Li et al., 2002).

\section{Implication of Laminin-DG Signaling in RPC Chromatin State Regulation}

Shorter S-phase has been suggested to mean that differentiating cells spend less time error checking than in cells that need to produce more progenitors to ensure fidelity of the passed genetic material (Arai et al., 2011). Though this interpretation is logically sound, there may be deeper implications of this observation. Lamb2 deletion, as well as blocking of $\alpha$-DG, resulted in shorter S-phase, with a higher ratio of late vs early S-phase RPCs. The number and location of replicons differ between early and late S-phase (Manders et al., 1992; Manders et al., 1996), and reflect the higher order chromosome organization. During early S-phase, euchromatic regions are replicated, while the stable heterochromatin is replicated later (O'Keefe et al., 1992). Increased numbers of late S-phase RPCs in $\mathrm{Lamb2}^{-/-}$mice suggest higher heterochromatin content. This is consistent with an increase in rate of differentiation, as stem cells have largely euchromatic genomes, that become more transcriptionally restricted and condensed as they differentiate (Efroni et al., 2008; Cremer and Cremer, 2010; R. A.; Young, 2011). Whether chromatin condensation is the direct result of ECM-mediated signaling, or is secondary to disrupted proliferative cues remains to be determined. In either case, the role of ECM in regulating chromatin state as it pertains to neurogenesis offers a very interesting avenue of studies. Our data presented here suggest that laminins in the ILM regulate the chromatin state of the RPCs, which could in turn, affect the expression of multiple genes. As the role of the ECM composition in regulation of gene expression has been well established (Bissell et al., 1982; Maniotis et al., 1997; Kheradmand et al., 1998; Engler et al., 2006; Le Beyec et al., 2007), it is possible that deletion of Lamb2 results in altered expression of signaling molecules that regulate the cell cycle progression and re-entry. The affected genes may include cell cycle regulators, various cytokines, and other ECM molecules that influence the stiffness of the ILM, which would affect the RPC cytoskeleton tension forces, as well as alter the biomolecular signaling properties of the surrounding ECM. Future studies would shed light on this phenomenon.

\section{DATA AVAILABILITY STATEMENT}

The original contributions presented in the study are included in the article/Supplementary Material, further inquiries can be directed to the corresponding author. 


\section{ETHICS STATEMENT}

The animal study was reviewed and approved by the Upstate Medical University IACUC.

\section{AUTHOR CONTRIBUTIONS}

DS performed, designed the experiments and collected the data and analyzed the results; GB performed some of the experiments and provided additional support and data collection; $\mathrm{DH}$ and $\mathrm{WB}$ designed the experiments; analyzed the data. DS prepared initial manuscript; $\mathrm{DH}$ and $\mathrm{WB}$ revised manuscript.

\section{FUNDING}

This work is funded in part by NIH-NEI grant R01-EY12676-17 to WJB and in part by an Unrestricted Grant to the Department

\section{REFERENCES}

Acilan, C., and Saunders, W. S. (2008). A Tale of Too Many Centrosomes. Cell 134, 572-575. doi:10.1016/j.cell.2008.08.007

Alexiades, M. R., and Cepko, C. (1996). Quantitative Analysis of Proliferation and Cell Cycle Length during Development of the Rat Retina. Dev. Dyn. 205, 293-307. doi:10.1002/(sici)1097-0177(199603)205:3<293:aid-aja9>3.0.co;2-d

Arai, Y., Pulvers, J. N., Haffner, C., Schilling, B., Nüsslein, I., Calegari, F., et al. (2011). Neural Stem and Progenitor Cells Shorten S-phase on Commitment to Neuron Production. Nat. Commun. 2, 154. doi:10.1038/ncomms1155

Baye, L. M., and Link, B. A. (2007a). Interkinetic Nuclear Migration and the Selection of Neurogenic Cell Divisions during Vertebrate Retinogenesis. J. Neurosci. 27, 10143-10152. doi:10.1523/JNEUROSCI.2754-07.2007

Baye, L. M., and Link, B. A. (2007b). The Disarrayed Mutation Results in Cell Cycle and Neurogenesis Defects during Retinal Development in Zebrafish. BMC Dev. Biol. 7, 28-16. doi:10.1186/1471-213X-7-28

Bershteyn, M., Nowakowski, T. J., Pollen, A. A., Di Lullo, E., Nene, A., WynshawBoris, A., et al. (2017). Human iPSC-Derived Cerebral Organoids Model Cellular Features of Lissencephaly and Reveal Prolonged Mitosis of Outer Radial Glia. Cell Stem Cell 20, 435-449. doi:10.1016/j.stem.2016.12.007

Bissell, M. J., Hall, H. G., and Parry, G. (1982). How Does the Extracellular Matrix Direct Gene Expression? J. Theor. Biol. 99, 31-68. doi:10.1016/0022-5193(82) 90388-5

Biswas, S., Bachay, G., Chu, J., Hunter, D. D., and Brunken, W. J. (2017). LamininDependent Interaction between Astrocytes and Microglia. Am. J. Pathol. 187, 2112-2127. doi:10.1016/j.ajpath.2017.05.016

Biswas, S., Watters, J., Bachay, G., Varshney, S., Hunter, D. D., Hu, H., et al. (2018). Laminin-dystroglycan Signaling Regulates Retinal Arteriogenesis. FASEB j. 32 (11), 6261-6273. doi:10.1096/fj.201800232R

Calegari, F., and Huttner, W. B. (2003). An Inhibition of Cyclin-dependent Kinases that Lengthens, but Does Not Arrest, Neuroepithelial Cell Cycle Induces Premature Neurogenesis. J. Cel Sci. 116, 4947-4955. doi:10.1242/jcs.00825

Calegari, F. (2005). Selective Lengthening of the Cell Cycle in the Neurogenic Subpopulation of Neural Progenitor Cells during Mouse Brain Development. J. Neurosci. 25, 6533-6538. doi:10.1523/JNEUROSCI.0778-05.2005

Clements, R., Turk, R., Campbell, K. P., and Wright, K. M. (2017). Dystroglycan Maintains Inner Limiting Membrane Integrity to Coordinate Retinal Development. J. Neurosci. 37, 8559-8574. doi:10.1523/JNEUROSCI.0946-17.2017

Cremer, T., and Cremer, M. (2010). Chromosome Territories. Cold Spring Harbor Perspect. Biol. 2, a003889. doi:10.1101/cshperspect.a003889

Dénes, V., Witkovsky, P., Koch, M., Hunter, D. D., Pinzón-duarte, G., and Brunken, W. J. (2007). Laminin Deficits Induce Alterations in the of Ophthalmology and Visual Sciences from the Research to Prevent Blindness. It is also funded in part by funds from the Upstate Medical University Faculty Incentive Programs.

\section{ACKNOWLEDGMENTS}

The authors would like to thank Dr. Heidi Hehnly (Syracuse University) for helpful discussions and feedback. The authors would also like to thank Dr. Kevin Campbell (HHMI, University of Iowa) for kindly providing the antibodies that were crucial for this work. Lastly, the authors would like to thank Dr. Reyna Martinez-De Luna (Upstate Medical University) and Jared Watters (Upstate Medical University) for critical reading and feedback on the manuscript. This work was supported by the National Institutes of Health [5R01 EY12676-15 to WB] and Research to Prevent Blindness [Unrestricted Grant to the Department of Ophthalmology and Visual Sciences].

Development of Dopaminergic Neurons in the Mouse Retina. Vis. Neurosci. 24, 549-562. doi:10.1017/S0952523807070514

Domogatskaya, A., Rodin, S., Boutaud, A., and Tryggvason, K. (2008). Laminin511 but Not -332, -111, or -411 Enables Mouse Embryonic Stem Cell SelfRenewal In Vitro. Stem Cells 26, 2800-2809. doi:10.1634/stemcells.2007-0389

Efroni, S., Duttagupta, R., Cheng, J., Dehghani, H., Hoeppner, D. J., Dash, C., et al. (2008). Global Transcription in Pluripotent Embryonic Stem Cells. Cell Stem Cell 2, 437-447. doi:10.1016/j.stem.2008.03.021

Engler, A. J., Sen, S., Sweeney, H. L., and Discher, D. E. (2006). Matrix Elasticity Directs Stem Cell Lineage Specification. Cell 126, 677-689. doi:10.1016/ j.cell.2006.06.044

Ervasti, J. M., and Campbell, K. P. (1991). Membrane Organization of the DystrophinGlycoprotein Complex. Cell 66, 1121-1131. doi:10.1016/0092-8674(91)90035-w

Ervasti, J. M., Ohlendieck, K., Kahl, S. D., Gaver, M. G., and Campbell, K. P. (1990). Deficiency of a Glycoprotein Component of the Dystrophin Complex in Dystrophic Muscle. Nature 345, 315-319. doi:10.1038/345315a0

Furuno, N., den Elzen, N., and Pines, J. (1999). Human Cyclin A Is Required for Mitosis until Mid Prophase. J. Cel Biol. 147, 295-306. doi:10.1083/jcb.147.2.295

Gérard, C., and Goldbeter, A. (2014). The Balance between Cell Cycle Arrest and Cell Proliferation: Control by the Extracellular Matrix and by Contact Inhibition. Interf. Focus. 4, 20130075. doi:10.1098/rsfs.2013.0075

Gnanaguru, G., Bachay, G., Biswas, S., Pinzón-Duarte, G., Hunter, D. D., and Brunken, W. J. (2013). Laminins Containing the $\beta 2$ and $\gamma 3$ Chains Regulate Astrocyte Migration and Angiogenesis in the Retina. Development 140, 2050-2060. doi:10.1242/dev.087817

Hand, R. (1978). Eucaryotic DNA: Organization of the Genome for Replication. Cell 15, 317-325. doi:10.1016/0092-8674(78)90001-6

Hirrlinger, P. G., Pannicke, T., Winkler, U., Claudepierre, T., Varshney, S., Schulze, C., et al. (2011). Genetic Deletion of Laminin Isoforms $\beta 2$ and $\gamma 3$ Induces a Reduction in Kir4.1 and Aquaporin-4 Expression and Function in the Retina. PLoS One 6, e16106. doi:10.1371/journal.pone.0016106

Holt, C. E., Bertsch, T. W., Ellis, H. M., and Harris, W. A. (1988). Cellular Determination in the xenopus Retina Is Independent of Lineage and Birth Date. Neuron 1, 15-26. doi:10.1016/0896-6273(88)90205-X

Hunter, D. D., and Brunken, W. J. (1997). $\beta \beta 2$ Laminins Modulate Neuronal Phenotype in the Rat Retina. Mol. Cell Neurosci. 10, 7-15. doi:10.1006/mone.1997.0632

Hunter, D. D., Manglapus, M. K., Bachay, G., Claudepierre, T., Dolan, M. W., Gesuelli, K.-A., et al. (2019). CNS Synapses Are Stabilized Trans-synaptically by Laminins and Laminin-Interacting Proteins. J. Comp. Neurol. 527, 67-86. doi: $10.1002 /$ cne. 24338

Hunter, D. D., Murphy, M. D., Olsson, C. V., and Brunken, W. J. (1992). S-laminin Expression in Adult and Developing Retinae: a Potential Cue for Photoreceptor Morphogenesis. Neuron 8, 399-413. doi:10.1016/0896-6273(92)90269-j 
Huttner, W. B., and Kosodo, Y. (2005). Symmetric versus Asymmetric Cell Division during Neurogenesis in the Developing Vertebrate central Nervous System. Curr. Opin. Cel Biol. 17, 648-657. doi:10.1016/j.ceb.2005.10.005

Jaunin, F., Visser, A. E., Cmarko, D., Aten, J. A., and Fakan, S. (1998). A New Immunocytochemical Technique for Ultrastructural Analysis of DNA Replication in Proliferating Cells after Application of Two Halogenated Deoxyuridines. J. Histochem. Cytochem. 46, 1203-1209. doi:10.1177/002215549804601014

Kheradmand, F., Werner, E., Tremble, P., Symons, M., and Werb, Z. (1998). Role of Rac1 and Oxygen Radicals in Collagenase-1 Expression Induced by Cell Shape Change. Science 280, 898-902. doi:10.1126/science.280.5365.898

Koohestani, F., Braundmeier, A. G., Mahdian, A., Seo, J., Bi, J., and Nowak, R. A. (2013). Extracellular Matrix Collagen Alters Cell Proliferation and Cell Cycle Progression of Human Uterine Leiomyoma Smooth Muscle Cells. PLoS ONE 8, e75844. doi:10.1371/journal.pone.0075844

Kuriyama, R., Terada, Y., Lee, K. S., and Wang, C. L. C. (2007). Centrosome Replication in Hydroxyurea-Arrested CHO Cells Expressing GFP-Tagged Centrin2. J. Cel Sci. 120, 2444-2453. doi:10.1242/jcs.008938

Le Beyec, J., Xu, R., Lee, S.-Y., Nelson, C. M., Rizki, A., Alcaraz, J., et al. (2007). Cell Shape Regulates Global Histone Acetylation in Human Mammary Epithelial Cells. Exp. Cel Res 313, 3066. doi:10.1016/j.yexcr.2007.04.022

Li, S., Harrison, D., Carbonetto, S., Fässler, R., Smyth, N., Edgar, D., et al. (2002). Matrix Assembly, Regulation, and Survival Functions of Laminin and its Receptors in Embryonic Stem Cell Differentiation. J. Cel Biol. 157, 1279-1290. doi:10.1083/jcb.200203073

Libby, R. T., Lavallee, C. R., Balkema, G. W., Brunken, W. J., and Hunter, D. D. (1999). Disruption of Laminin $\beta 2$ Chain Production Causes Alterations in Morphology and Function in the CNS. J. Neurosci. 19, 9399-9411. doi:10.1523/jneurosci.19-21-09399.1999

Libby, R. T., Xu, Y., Selfors, L. M., Brunken, W. J., and Hunter, D. D. (1997). Identification of the Cellular Source of Laminin $\beta 2$ in Adult and Developing Vertebrate Retinae. J. Comp. Neurol. 389, 655-667. doi:10.1002/(sici)10969861(19971229)389:4<655:aid-cne8>3.0.co;2-\#

Ma, H., Samarabandu, J., Devdhar, R. S., Acharya, R., Cheng, P.-c., Meng, C., et al. (1998). Spatial and Temporal Dynamics of DNA Replication Sites in Mammalian Cells. J. Cel Biol. 143, 1415-1425. doi:10.1083/jcb.143.6.1415

Manders, E. M., Stap, J., Brakenhoff, G. J., van Driel, R., and Aten, J. A. (1992). Dynamics of Three-Dimensional Replication Patterns during the S-phase, Analysed by Double Labelling of DNA and Confocal Microscopy. J. Cel Sci 103 (Pt 3), 857-862. doi:10.1242/jcs.103.3.857

Manders, E. M. M., Stap, J., Strackee, J., van Driel, R., and Aten, J. A. (1996). Dynamic Behavior of DNA Replication Domains. Exp. Cel Res. 226, 328-335. doi:10.1006/ excr.1996.0233

Maniotis, A. J., Chen, C. S., and Ingber, D. E. (1997). Demonstration of Mechanical Connections between Integrins, Cytoskeletal Filaments, and Nucleoplasm that Stabilize Nuclear Structure. Proc. Natl. Acad. Sci. 94, 849-854. doi:10.1073/pnas.94.3.849

Moore, S. A., Saito, F., Chen, J., Michele, D. E., Henry, M. D., Messing, A., et al. (2002). Deletion of Brain Dystroglycan Recapitulates Aspects of Congenital Muscular Dystrophy. Nature 418, 422-425. doi:10.1038/nature00838

Morin, X., and Bellaiche, Y. (2011). Mitotic Spindle Orientation in Asymmetric and Symmetric Cell Divisions. Dev. Cel 21, 102. doi:10.1016/j.devcel.2011.06.012

Noakes, P. G., Gautam, M., Mudd, J., Sanes, J. R., and Merlie, J. P. (1995). Aberrant Differentiation of Neuromuscular Junctions in Mice Lacking S-Laminin/laminin $\beta 2$. Nature 374, 258-262. doi:10.1038/374258a0

Novorol, C., Burkhardt, J., Wood, K. J., Iqbal, A., Roque, C., Coutts, N., et al. (2013). Microcephaly Models in the Developing Zebrafish Retinal Neuroepithelium point to an Underlying Defect in Metaphase Progression. Open Biol. 3, 130065. doi:10.1098/rsob.130065

Nowakowski, R. S., Lewin, S. B., and Miller, M. W. (1989). Bromodeoxyuridine Immunohistochemical Determination of the Lengths of the Cell Cycle and the DNA-Synthetic Phase for an Anatomically Defined Population. J. Neurocytol 18, 311-318. doi:10.1007/BF01190834

O’Keefe, R. T., Henderson, S. C., and Spector, D. L. (1992). Dynamic Organization of DNA Replication in Mammalian Cell Nuclei: Spatially and Temporally Defined Replication of Chromosome-specific Alpha-Satellite DNA Sequences. J. Cel Biol. 116, 1095-1110. doi:10.1083/jcb.116.5.1095

Pacal, M., and Bremner, R. (2012). Mapping Differentiation Kinetics in the Mouse Retina Reveals an Extensive Period of Cell Cycle Protein Expression in postmitotic Newborn Neurons. Dev. Dyn. 241, 1525-1544. doi:10.1002/dvdy.23840
Pilaz, L.-J., McMahon, J. J., Miller, E. E., Lennox, A. L., Suzuki, A., Salmon, E., et al. (2016). Prolonged Mitosis of Neural Progenitors Alters Cell Fate in the Developing Brain. Neuron 89, 83-99. doi:10.1016/j.neuron.2015.12.007

Pilaz, L.-J., Patti, D., Marcy, G., Ollier, E., Pfister, S., Douglas, R. J., et al. (2009). Forced G1-phase Reduction Alters Mode of Division, Neuron Number, and Laminar Phenotype in the Cerebral Cortex. Proc. Natl. Acad. Sci. 106, 21924-21929. doi:10.1073/pnas.0909894106

Pinzón-Duarte, G., Daly, G., Yong, L., Hunter, D. D., Koch, M., and Brunken, W. J. (2010). Defective Formation of the Inner Limiting Membrane in Laminin $\beta 2$ and $\gamma 3$-null Mice Produces Retinal Dysplasia. Invest. Ophthalmol. Vis. Sci. 51, 1773-1782. doi:10.1016/j.exer.2012.01.007

Quastler, H., and Sherman, F. G. (1959). Cell Population Kinetics in the Intestinal Epithelium of the Mouse. Exp. Cel Res. 17, 420-438. doi:10.1016/0014-4827(59) 90063-1

Radner, S., Banos, C., Bachay, G., Li, Y. N., Hunter, D. D., Brunken, W. J., et al. (2012). $\beta 2$ and $\gamma 3$ Laminins Are Critical Cortical Basement Membrane Components: Ablation of Lamb2 and Lamc3 Genes Disrupts Cortical Lamination and Produces Dysplasia. Devel Neurobio 73, 209-229. doi:10.1002/dneu.22057

Rossetto, D., Avvakumov, N., and Côté, J. (2012). Histone Phosphorylation. Epigenetics 7, 1098-1108. doi:10.4161/epi.21975

Satz, J. S., Ostendorf, A. P., Hou, S., Turner, A., Kusano, H., Lee, J. C., et al. (2010). Distinct Functions of Glial and Neuronal Dystroglycan in the Developing and Adult Mouse Brain. J. Neurosci. 30, 14560-14572. doi:10.1523/JNEUROSCI.3247-10.2010

Serjanov, D., Bachay, G., Hunter, D. D., and Brunken, W. J. (2018). Laminin $\beta 2$ Chain Regulates Retinal Progenitor Cell Mitotic Spindle Orientation via Dystroglycan. J. Neurosci. 38, 5996-6010. doi:10.1523/JNEUROSCI.0551-18.2018

Sluder, G., and Nordberg, J. J. (2004). The Good, the Bad and the Ugly: the Practical Consequences of Centrosome Amplification. Curr. Opin. Cel Biol. 16, 49-54. doi:10.1016/j.ceb.2003.11.006

Sluder, G. (2005). Two-way Traffic: Centrosomes and the Cell Cycle. Nat. Rev. Mol. Cel Biol 6, 743-748. doi:10.1038/nrm1712

Stearns, T. (2001). Centrosome Duplication. Cell 105, 417-420. doi:10.1016/ s0092-8674(01)00366-x

Therman, E., Buchler, D. A., Nieminen, U., and Timonen, S. (1984). Mitotic Modifications and Aberrations in Human Cervical Cancer. Cancer Genet. Cytogenet. 11, 185-197. doi:10.1016/0165-4608(84)90113-4

Turner, D. L., and Cepko, C. L. (1987). A Common Progenitor for Neurons and Glia Persists in Rat Retina Late in Development. Nature 328, 131-136. doi: $10.1038 / 328131 \mathrm{a} 0$

Turner, D. L., Snyder, E. Y., and Cepko, C. L. (1990). Lineage-independent Determination of Cell Type in the Embryonic Mouse Retina. Neuron 4, 833-845. doi:10.1016/0896-6273(90)90136-4

Yamada, K., Semba, R., Ding, X., Ma, N., and Nagahama, M. (2005). Discrimination of Cell Nuclei in Early S-phase, Mid-to-late S-phase, and G2/M-phase by Sequential Administration of 5-Bromo-2'-Deoxyuridine and 5-Chloro-2'-Deoxyuridine. J. Histochem. Cytochem. 53, 1365-1370. doi:10.1369/jhc.4A6601.2005

Young, R. A. (2011). Control of the Embryonic Stem Cell State. Cell 144, 940-954. doi:10.1016/j.cell.2011.01.032

Young, R. W. (1985). Cell Differentiation in the Retina of the Mouse. Anat. Rec. 212, 199-205. doi:10.1002/ar.1092120215

Conflict of Interest: The authors declare that the research was conducted in the absence of any commercial or financial relationships that could be construed as a potential conflict of interest.

Publisher's Note: All claims expressed in this article are solely those of the authors and do not necessarily represent those of their affiliated organizations, or those of the publisher, the editors and the reviewers. Any product that may be evaluated in this article, or claim that may be made by its manufacturer, is not guaranteed or endorsed by the publisher.

Copyright $\odot 2022$ Serjanov, Bachay, Hunter and Brunken. This is an open-access article distributed under the terms of the Creative Commons Attribution License (CC BY). The use, distribution or reproduction in other forums is permitted, provided the original author(s) and the copyright owner(s) are credited and that the original publication in this journal is cited, in accordance with accepted academic practice. No use, distribution or reproduction is permitted which does not comply with these terms. 